\title{
Review on enhanced oil recovery by nanofluids
}

\author{
Kewen $\mathrm{Li}^{1,2,3, *}$, Dan Wang ${ }^{1}$, and Shanshan Jiang ${ }^{1}$ \\ ${ }^{1}$ School of Energy Resources, China University of Geosciences (Beijing), 29 Xueyuan Road, Beijing 100083, China \\ ${ }^{2}$ Key Laboratory of Marine Reservoir Evolution and Hydrocarbon Enrichment Mechanism, Ministry of Education, \\ 29 Xueyuan Road, Beijing 100083, China \\ ${ }^{3}$ Department of Energy Resources Engineering, Stanford University, Stanford, CA 94305, USA
}

Received: 16 February 2018 / Accepted: 18 June 2018

\begin{abstract}
The addition of nanoparticles into water based fluids (nanofluid) with or without other chemicals to Enhance Oil Recovery (EOR) has recently received intensive interest. Many papers have been published in this area and several EOR mechanisms have been proposed. The main EOR mechanisms include wettability alteration, reduction in InterFacial surface Tension (IFT), increase in the viscosity of aqueous solution, decrease in oil viscosity, and log-jamming. Some of these mechanisms may be associated with the change in disjoining pressure because of the addition of the nanoparticles. The experimental data and results reported by different researchers, however, are not all consistent and some even conflict with others. Many papers published in recent years have been reviewed and the associated experimental data have been analyzed in this paper in order to clarify the mechanisms of EOR by nanofluids. Wettability alteration may be one of the most accepted mechanisms for nanofluid EOR while reduction in IFT and other mechanisms have not been fully proven. The main reason for the inconsistency among the experimental data might be lack of control experiments in which the effect of nanoparticles on oil recovery would be singled out.
\end{abstract}

\section{Introduction}

A nanofluid is simply a liquid with nanoparticles of specific functions in the form of stable colloidal suspension. Nanofluid is a two-phase fluid system with a solid phase (nanoparticles) in a liquid phase. The nanoparticles can move freely through the liquid molecules by following a random path governed with Brownian motion. One of the important issues for the two-phase nanofluid is the stability of the nanoparticles. The nanoparticles are so small in size and so light in weight that often they can remain suspended in the base liquid, regardless of the gravity effect. The stability, however, may be affected by other factors such as van der Waals forces and the surface charges of the nanoparticles. As Moon (2010) pointed out, the stability of nanofluid is determined by the sum of the attractive (and repulsive) van der Waals forces between the particles. If the particle repulsive forces exceed the attractive forces, the suspensions will be stable and aggregation is avoided (Yu and Xie, 2012). Nanofluid can be stabilized by altering charge density and zeta potential of the nanoparticles (Mcelfresh et al. 2012).

The experimental results reported in many papers demonstrated noticeably that nanofluids could improve

\footnotetext{
* Corresponding author: likewen@cugb.edu.cn
}

or increase oil recovery although the values of EOR are dependent on the properties of the nanofluids such as the size, concentration, material types of the nanoparticle. For example, $\mathrm{Hu}$ et al. (2016) reported a remarkable $31.4 \%$ increase of oil recovery at breakthrough. Many potential mechanisms have been proposed by different researchers for nanofluid EOR (Wasan et al., 2011; Torsater et al., 2013a, 2013b). These mechanisms include: (1) wettability alteration to more water-wetness, (2) reduction in InterFacial surface Tension (IFT) of oil/water systems, (3) change in disjoining pressure, (4) increase in the viscosity of aqueous solution, (5) decrease in oil viscosity, (6) climbing film and slug-like displacement (Luo et al., 2016), (7) log-jamming: nanoparticles block some pores and then force oil to be produced from adjunct pores where it was previously trapped, (8) combination of different mechanisms, and (9) other mechanisms.

Some of these mechanisms may not be independent. For example, the first two mechanisms may be dependent on disjoining pressure. Each of these mechanisms will be analyzed and discussed in the next sections based on most of the recent publications. Some of the typical parameters of nanoparticles, nanofluid, rocks, fluid property, and oil recovery from these publications are listed in Table 1.

Nanotechnology has been a hot spot for research in petroleum industry in recent years (Kanj et al., 2009; 
Onyekonwu and Ogolo, 2010; Haroun et al., 2012; Ogolo et al., 2012; Alaskar et al., 2012; Zhang et al., 2016). Many achievements have been obtained in a number of aspects such as drilling, reservoir monitoring, Enhanced Oil Recovery (EOR), etc. Nonetheless there are still many opportunities to be addressed in the area of nanotechnology for EOR. One of the problems is that the mechanisms behind nanofluid-EOR are not very clear or not fully understood, more importantly, are not widely accepted. For example, one of the reported mechanisms is the creation of wedge-film structure in the three-phase (oil-water-rock) contact area (Wasan et al., 2011) for wettability alteration. However, this explanation does not have a solid experimental verification and, to some extent, is a speculation. More profound understanding of the mechanisms is essential. Another problem is the oil recovery increase by use of nanofluid has been limited, usually less than $10 \%$, in many cases and it takes a large Pore Volume (PV) of 1-2 PV to mobilize the remaining oil at the core scale, as reported by many researchers (for example, Torsater et al., 2013a). The incremental oil recovery by use of nanofluids is much less than in routine surfactant flooding. On the other hand, in some cases the increase of oil recovery by nanofluid is very high. The reasons and mechanisms behind these experimental results are not completely recognized and fully accepted.

A few papers have reviewed the nanotechnology for EOR (Ayatollahi and Zerafat, 2012; Friedheim et al., 2012; Bennetzen and Mogensen, 2014; ShamsiJazeyi et al., 2014; Negin et al., 2016; Cheraghian and Hendraningrat, 2016a, 2016b; Idogun et al., 2016; Sun et al., 2017). Ayatollahi and Zerafat (2012) summarized the new findings from several different theoretical, analytical and experimental works which showed the effectiveness of traditional methods when assisted by the nanotechnology. They proposed that InterFacial Tension (IFT) reduction, wettability alteration and fine fixation by nanotechnology are more applicable than nanosensors, nanocatalysts and nanofiltration for a short term. Friedheim et al. (2012) reviewed the studies on the application of nanotechnology in shale stabilization, high-temperature tolerance and viscosity modification. They also discussed the results from projects that utilized graphene as well as graphene derivatives, Carbon NanoTubes (CNT), nanosilica and other nanochemistries to achieve and enhance the performance of drilling fluids. Friedheim et al. (2012) further addressed some of the concerns and pitfalls of sourcing and using commercial "nano" products and current health and safety perspective on the nanotechnology for the petroleum industry. Cheraghian and Hendraningrat (2016a and 2016b) reviewed the application of nanotechnology in chemical flooding process in oil recovery, including polymer and surfactant flooding.

Most of these review papers have paid attention on the general applications of nanotechnology but have not analyzed the mechanisms of EOR by nanofluids systematically. The purpose of this review was to clarify the mechanisms of EOR by nanofluids and the problems that may have existed in the experiments by examining and analysing most of the papers published in recent years and the associated experimental data.
Firstly, we describe the mechanisms of EOR by using nanofluids and the related technologies, mainly based on the reports and publications by different researchers. Secondly, we discuss the advantages and disadvantages of the nanofluid EOR technology briefly. Finally, we discuss, summarize, and clarify the mechanisms of EOR by nanofluids.

\section{The mechanisms of nanofluid EOR}

\subsection{Wettability alteration to more water wetness}

It is well-known that wettability is one of the important factors that affect the oil recovery. The wettability of rock-oil-water systems may be altered by the addition of nanoparticles in the water phase that creates a wedge-film structure in the three-phase contact area as reported by Wasan et al. in 2011. As pointed out by Wasan et al. (2011), ordered structures formed by nanoparticles are located near the three-phase contact line (wetting wedge) of a drop or bubble on a solid surface (Fig. 1), which promotes the spreading of liquids containing nanoparticles (nanofluids) and makes the system more water-wet. The detailed theory behind this is still not very clear. Understanding the complex nature of the interactions between the particles in the nanofluid and with the solid substrate is critical to the comprehension of the enhanced spreading behavior of nanofluids on solids under the action of the structural disjoining pressure gradient.

Karimi et al. (2012) studied the effect of wettability alteration in carbonates using zirconium oxide $\left(\mathrm{ZrO}_{2}\right)$ nanofluids on oil recovery. They reported that the contact angle of $n$-heptane/water on the cleaned calcite plates aged in the crude oil was $180^{\circ}$. The treatments of seven different nanofluids could alter the contact angles on the aged plated, as shown in Figure 2. The surfactant solution without nanoparticles (Fluid 1) altered the wetting property from oil-wet (the contact angle was $180^{\circ}$ ) to an intermediate state (the contact angle was about $90^{\circ}$ ). Karimi et al. (2012) showed that introducing the nanoparticles into the solution resulted in wetting alteration from oil-wet to strongly water-wet conditions. All the fluids except Fluid $1 \quad\left(\mathrm{ZrO}_{2}\right.$ nanoparticle concentration $\left.=0.0 \%\right)$ contained nanoparticles, however, only Fluid $2\left(\mathrm{ZrO}_{2}\right.$ nanoparticle concentration $=0.05 \mathrm{wt} \%)$ and Fluid $7\left(\mathrm{ZrO}_{2}\right.$ nanoparticle concentration $=0.05 \mathrm{wt} \%$ ) could alter the wettability from strong oil-wetness (the contact angle was $180^{\circ}$ ) to waterwetness (the contact angle was around $32^{\circ}$ ). Note that the contact angle of $180^{\circ}$ reported by Karimi et al. (2012) is surprising and uncommon in the literature.

Karimi et al. (2012) also found that the values of the contact angles between water and $n$-heptane on samples aged in Fluid 2 decrease with the increase in aging time (Fig. 3). According to the results, they suggested that a minimum of $48 \mathrm{~h}$ of aging time is required for wettability alteration from oil- to water-wetness.

The oil recovery could be enhanced by Fluid 2 according to the experimental results of spontaneous imbibitions from Karimi et al. (2012), as shown in Figure 4. It would be much 
Table 1. Summary on the study of nanofluid EOR.

\begin{tabular}{|c|c|c|c|c|c|c|c|c|c|}
\hline Authors & Date & Sources & Mechanisms & Chemicals & Nanoparticle & $\begin{array}{c}\text { IFT } \\
\text { change }(\%)\end{array}$ & $\begin{array}{c}\theta \text { change } \\
(\%)\end{array}$ & Rocks & $\begin{array}{c}\text { EOR } \\
(\%)\end{array}$ \\
\hline $\begin{array}{l}\text { Suleimanov } \\
\text { et al. }\end{array}$ & 2011 & JPSE & $\begin{array}{l}\text { Reduce IFT } \\
\text { Decrease } \theta \\
\text { Increase } \\
\mu_{\mathrm{w}}, 2 \mathrm{cp}\end{array}$ & $\begin{array}{l}\text { Anionic, Sodium } \\
\text { 4-alkyl- } \\
\text { 2ylbenzenesulfonate }\end{array}$ & $\begin{array}{l}\text { Nanoparticle: } \\
\text { nonferrous metal } \\
\text { Size: } 70-150 \mathrm{~nm} \\
\text { C: } 0.001 \% \mathrm{wt} \\
\text { D: } 0.32-0.37 \mathrm{~g} / \mathrm{cm}^{3} \\
\text { Oil: } 7 \mathrm{cp} \\
\text { PH: NA }\end{array}$ & $\begin{array}{c}70-90 \\
(10.9-1.04 \\
\text { dynes } / \mathrm{cm})\end{array}$ & $\begin{array}{c}17 \\
\left(23-19^{\circ}\right)\end{array}$ & $\begin{array}{c}\text { Rock: NA } \\
\phi=26 \% \\
k=1000 \mathrm{md}\end{array}$ & $12-17$ \\
\hline $\begin{array}{l}\text { Metin } \\
\text { et al. }\end{array}$ & 2012 & $\begin{array}{l}\text { Nanopart } \\
\text { Res }\end{array}$ & None & $\begin{array}{l}\text { Cationic (quaternary } \\
\text { ammonium (quat)) or } \\
\text { nonionic polyethylene } \\
\text { glycol (PEG) }\end{array}$ & $\begin{array}{l}\text { Nanoparticle: silica } \\
\text { Size: } 5-75 \mathrm{~nm} \\
\text { C: } 0.04,0.2, \& 1 \% \\
\text { D: NA } \\
\text { Oil: decane } \\
\text { PH: NA }\end{array}$ & $\begin{array}{c}4(45-43 \\
\text { dynes/cm) }\end{array}$ & $\begin{array}{c}22 \\
\left(59-46^{\circ}\right)\end{array}$ & $\begin{array}{c}\text { Rock: NA } \\
\phi=\mathrm{NA} \\
k=\mathrm{NA}\end{array}$ & NA \\
\hline $\begin{array}{l}\text { Karimi } \\
\text { et al. }\end{array}$ & 2012 & $\begin{array}{l}\text { Energy } \\
\& \text { Fuels }\end{array}$ & Decrease $\theta$ & $\begin{array}{l}\text { Tween } 80 \\
\text { Span } 85 \\
\text { Glycerin } \\
\text { LA2 }\end{array}$ & $\begin{array}{l}\text { Nanoparticle: } \\
\text { zirconium oxide } \\
\text { Size: } 24 \mathrm{~nm} \\
\text { C: } 0.05,0.10 \mathrm{gr} / \mathrm{cc} \\
\text { D: NA } \\
\text { Oil: } n \text {-heptane } \\
\text { PH: } 2-3\end{array}$ & NA & $\left(180-32^{\circ}\right)$ & $\begin{array}{c}\text { Rock: } \\
\text { Carbonate } \\
\phi=20 \% \\
k=30 \mathrm{md}\end{array}$ & 10 \\
\hline $\begin{array}{l}\text { Zhang } \\
\text { et al. }\end{array}$ & $2014 a$ & $\begin{array}{l}\text { Energy } \\
\text { \& Fuels }\end{array}$ & $\begin{array}{l}\text { Reduce IFT } \\
\text { Decrease } \theta\end{array}$ & $\begin{array}{l}\text { IIT nanofluid } \\
\text { (no details) }\end{array}$ & $\begin{array}{l}\text { Nanoparticle: silica } \\
\text { Size: } 20 \mathrm{~nm} \\
\text { C: } 10 \% \text { vol. } \\
\text { D: } 1.15 \mathrm{~g} / \mathrm{cm}^{3} \\
\text { Oil: crude, } 94.88 \mathrm{cp}\left(25^{\circ} \mathrm{C}\right) \\
\text { PH: } 9.7\end{array}$ & $\begin{array}{l}91(16-1.4 \\
\text { dynes } / \mathrm{cm})\end{array}$ & $\begin{array}{c}98 \\
\left(74-1.2^{\circ}\right)\end{array}$ & $\begin{array}{l}\text { Rock: Berea } \\
\text { sandstone } \\
\phi=20 \% \\
k=400 \mathrm{md}\end{array}$ & 33 \\
\hline $\begin{array}{l}\text { Moradi } \\
\text { et al. }\end{array}$ & 2015 & $\begin{array}{l}\text { SPE } \\
178040\end{array}$ & $\begin{array}{l}\text { Reduce IFT } \\
\text { Decrease } \theta\end{array}$ & $\begin{array}{l}\text { No chemicals } \\
\text { added }\end{array}$ & $\begin{array}{l}\text { Nanoparticle: silica } \\
\text { Size: } 11-14 \mathrm{~nm} \\
\text { C: } 0.1 \% \text { mass } \\
\text { D: NA } \\
\text { Oil: } \\
\text { crude, } 30.3 \mathrm{cp}\left(60^{\circ} \mathrm{F}\right) \\
\text { PH: } 9.7\end{array}$ & $\begin{array}{c}21 \\
(13.62-10.69 \\
\text { dynes } / \mathrm{cm})\end{array}$ & $\begin{array}{c}87 \\
\left(122-16^{\circ}\right)\end{array}$ & $\begin{array}{c}\text { Rock: } \\
\text { Carbonate } \\
\phi=10.33 \% \\
k=2.839 \mathrm{md}\end{array}$ & 23.5 \\
\hline $\begin{array}{l}\text { Hendraningrat } \\
\text { et al. }\end{array}$ & 2013 & JPSE & $\begin{array}{l}\text { Reduce IFT } \\
\text { Decrease } \theta\end{array}$ & $\begin{array}{l}\text { Povidone: } \\
\text { PolyVinylPyrroli } \\
\text { done (PVP) }\end{array}$ & $\begin{array}{l}\text { Nanoparticle: silica } \\
\text { Size: } 21-40 \mathrm{~nm} \\
\text { C: } 0.01-1.0 \% \text { mass } \\
\text { D: NA } \\
\text { Oil: crude, } 5.1 \mathrm{cp}\left(21.4^{\circ} \mathrm{C}\right) \\
\text { PH: } 3-5\end{array}$ & $\begin{array}{c}58.9 \\
(19.2-7.9 \\
\text { dynes/cm) }\end{array}$ & $\begin{array}{c}59.3 \\
\left(54-22^{\circ}\right)\end{array}$ & $\begin{array}{c}\text { Rock: Berea } \\
\text { sandstone } \\
\phi=13.93^{-} \\
23.20 \% \\
k=9-400 \mathrm{md}\end{array}$ & $0-6.1$ \\
\hline
\end{tabular}


Table 1. (continued)

\begin{tabular}{|c|c|c|c|c|c|c|c|c|c|}
\hline Authors & Date & Sources & Mechanisms & Chemicals & Nanoparticle & $\begin{array}{c}\text { IFT change } \\
(\%)\end{array}$ & $\begin{array}{c}\theta \text { change } \\
(\%)\end{array}$ & Rocks & $\begin{array}{c}\text { EOR } \\
(\%) \\
\end{array}$ \\
\hline $\begin{array}{l}\text { Hendraningrat } \\
\text { and Torsaeter }\end{array}$ & 2014 & $\begin{array}{l}\text { OTC } \\
24696\end{array}$ & Decrease $\theta$ & $\begin{array}{l}\text { Povidone: } \\
\text { PolyVinylPyrroli } \\
\text { done (PVP) }\end{array}$ & $\begin{array}{l}\text { Nanoparticle: aluminium, } \\
\text { titanium, silica } \\
\text { Size: } 17-40 \mathrm{~nm} \\
\text { C: } 0.05 \% \text { mass } \\
\text { D: } 1.01-1.02 \mathrm{~g} / \mathrm{cm}^{3} \\
\text { Oil: crude, } 5-50 \mathrm{cp}\left(22^{\circ} \mathrm{C}\right) \\
\text { PH: } 3-6\end{array}$ & $\mathrm{NA}$ & $\begin{array}{c}61.1 \\
\left(54-21^{\circ}\right)\end{array}$ & $\begin{array}{l}\text { Rock: Berea } \\
\text { sandstone } \\
\phi=15 \% \\
k=60 \mathrm{md}\end{array}$ & $7-24$ \\
\hline $\begin{array}{l}\text { Ogolo } \\
\text { et al. }\end{array}$ & 2012 & $\begin{array}{l}\text { SPE } \\
160847\end{array}$ & $\begin{array}{l}\text { Reduce IFT } \\
\text { Reduce } \mu_{0} \\
\text { Change } \theta\end{array}$ & Ethanol & $\begin{array}{l}\text { Nanoparticle: } \mathrm{Al}_{2} \mathrm{O}_{3} \text { et al. } \\
\text { Size: } 10-70 \mathrm{~nm} \\
\mathrm{C}: 3 \mathrm{~g} / \mathrm{LD}: \mathrm{NA} \\
\text { Oil: } 55.3 \mathrm{cp}\left(27^{\circ} \mathrm{C}\right) \\
\text { PH: NA }\end{array}$ & NA & NA & Sand pack & 12 \\
\hline $\begin{array}{l}\text { Mcelfresh } \\
\text { et al. }\end{array}$ & 2012 & $\begin{array}{l}\text { SPE } \\
154827\end{array}$ & $\begin{array}{l}\text { Reduce IFT } \\
\text { Decrease } \theta\end{array}$ & NA & $\begin{array}{l}\text { Nanoparticle: silica } \\
\text { Size: } 4-20 \mathrm{~nm} \\
\text { C: } 10 \% \\
\text { D: NA } \\
\text { Oil: San Andres crude oil } \\
\text { PH: NA }\end{array}$ & NA & NA & $\begin{array}{c}\text { Rock: Berea } \\
\text { sandstone } \\
\phi=20 \% \\
k=40 \\
160 \mathrm{md}\end{array}$ & $\begin{array}{l}22 \text { for } \\
\text { imbibition }\end{array}$ \\
\hline $\begin{array}{l}\text { El-Diasty } \\
\text { and Aly }\end{array}$ & 2015 & $\begin{array}{l}\text { SPE- } \\
175806\end{array}$ & $\begin{array}{l}\text { Change SDP } \\
\text { Change } \theta \\
\text { Log-jamming }\end{array}$ & & $\begin{array}{l}\text { Nanoparticle: silica } \\
\text { Size: } 5-60 \mathrm{~nm} \\
\text { C: } 0.01-3 \% \text { wt } \\
\text { D: NA } \\
\text { Oil: Mineral oil ( } 27.3 \mathrm{API}) \\
\text { PH: NA }\end{array}$ & NA & NA & $\begin{array}{c}\text { Rock: } \\
\text { sandstone } \\
\phi=26 \% \\
k=378.73 \mathrm{md}\end{array}$ & $5-35$ \\
\hline Luo et al. & 2016 & PNAS & $\begin{array}{l}\text { Climbing film } \\
\text { Slug-like } \\
\text { displacement }\end{array}$ & & $\begin{array}{l}\text { Nanoparticle: amphiphilic } \\
\text { graphene nanosheets } \\
\text { Size: } 1 \mathrm{~nm} \text { (thickness) } \\
\text { C: } 0.01 \% \text { D: NA } \\
\text { Oil: Heptane } \\
\text { PH: NA }\end{array}$ & $\mathrm{NA}$ & NA & $\begin{array}{c}\text { Rock: } \\
\text { artificial rock } \\
\phi=24.8-27.9 \% \\
k=44.5-132 \mathrm{md}\end{array}$ & $6.7-15.2$ \\
\hline $\mathrm{Hu}$ et al. & 2016 & $\begin{array}{l}\text { Energy } \\
\text { \& Fuels }\end{array}$ & $\begin{array}{l}\text { Change } \theta \\
\text { Change mobility } \\
\text { Log-jamming }\end{array}$ & $\begin{array}{l}\text { Polymer } \\
\text { surfactant }\end{array}$ & $\begin{array}{l}\text { Nanoparticle: } \mathrm{TiO}_{2} \\
\text { Size: } 150 \pm 20 \mathrm{~nm} \\
\text { C: } 10-500 \mathrm{ppm} \\
\text { D: NA } \\
\text { Oil: HVI } 60 \text { mineral oil, } \\
42.75 \mathrm{cp}\left(25^{\circ} \mathrm{C}\right) \\
\text { PH: } 6.72 \\
\text { Zeta: }-32.0 \pm 1.0 \mathrm{mV}\end{array}$ & $\begin{array}{c}\text { Not } \\
\text { monotonic } \\
(47.5-49.0 \\
\text { then } 44.5 \\
\text { dynes } / \mathrm{cm})\end{array}$ & $\begin{array}{c}55.6 \\
(18-8)\end{array}$ & $\begin{array}{c}\text { Rock: Berea } \\
\text { sandstone } \\
\phi=18-25 \% \\
k=100-1000 \mathrm{md}\end{array}$ & $9.5-13.3$ \\
\hline
\end{tabular}




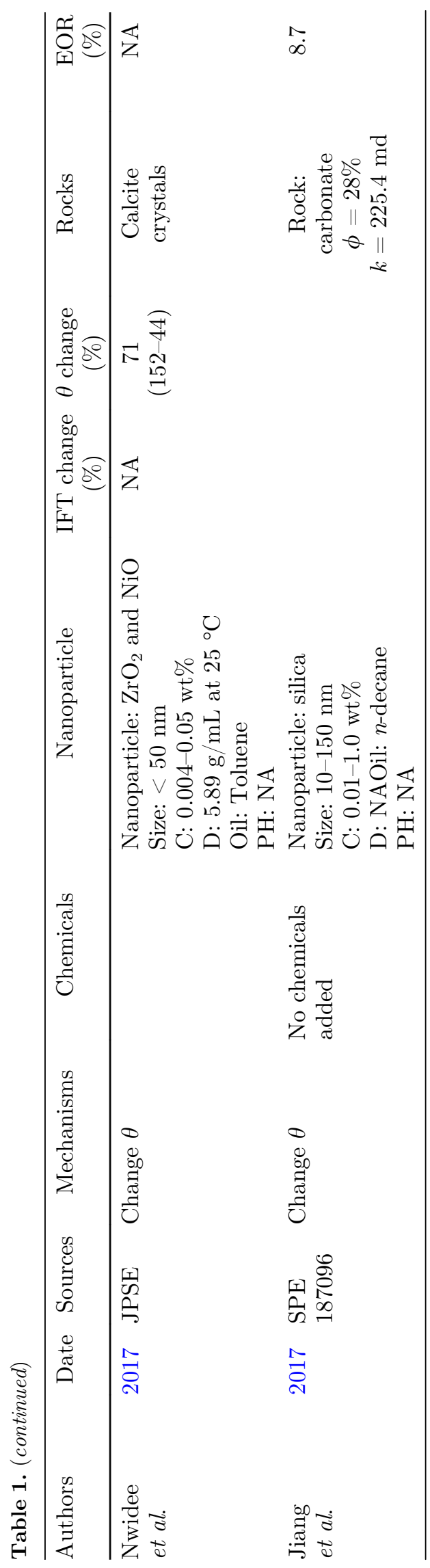

better to clarify the effect of the nanoparticles if the oil recovery by Fluid 1 without nanoparticles had been reported by Karimi et al. (2012). The only difference among Fluids 1, 2 and 3 is the nanoparticle concentration. The concentrations of the nanoparticles in Fluids 1, 2, and 3 were $0.00,0.05$, and $0.10 \%$ respectively. The oil recovery from spontaneous imbibition by distilled water would be zero because of the strong oil-wetness (the contact angle was $180^{\circ}$ in this case, as reported by Karimi et al., 2012).

Karimi et al. (2012) proposed a model to explain the mechanism of EOR they observed. It is difficult, however, to explain the difference in the oil recovery between Fluids 2 and 3 using this model. It would be helpful for them to provide the values of IFT in the different systems.

Mcelfresh et al. (2012) utilized aqueous stabilized nanoparticle dispersions with 4-20 $\mathrm{nm}$ silicon dioxide particles and demonstrated in both experimental laboratory evaluations and field trials to provide production improvements in wellbore remediation and increased injectivity over conventional treatments. Spontaneous imbibition tests were conducted. The oil-saturated core samples were immersed into a test liquid that contained $10 \%$ nanoparticle dispersion. As shown in Figure 5, the amount of oil (31\%) displaced and released from the core by nanoparticle liquid spontaneous imbibition was considerably higher than that $(9 \%)$ of a $2 \% \mathrm{KCl}$ control brine with the same surfactant formulation. It seems that the oil droplets displaced by nanoparticle liquid imbibition were easier to get off the surface of the rock sample.

Mcelfresh et al. (2012) also conducted core flooding tests which showed very low residual oil saturations after injecting 10 pore volumes of the $10 \%$ nanoparticle dispersion liquid. They did not present the core flooding results by brine. It is difficult to identify the effect of nanofluid without a control test. Structural Equation Modeling (SEM) analysis was performed to observe the microscopic distribution of nanoparticles inside the rock. The SEM images of the core samples that had been treated with 10 pore volumes of a $10 \%$ nanoparticle formulation illustrated the nanoparticle affinity for a discontinuous phase along a substrate. Figure 6 shows the alignment of nanoparticles along an illite clay ribbon on a sandstone surface. It would be useful and interesting if the distribution of nanoparticles inside the rock could be shown when both oil and water reside in the rock.

Mcelfresh et al. (2012) conducted over 50 successful beta field test applications after completing the laboratory studies. The overall effect of the nanoparticle fluid is longer retreatment times as well as higher productivity/injectivity for longer periods. Note that Mcelfresh et al. (2012) did not measure the IFT and contact angles to show the wettability alteration.

Hendraningrat and Torsaeter (2014) employed two water-based metal-oxide nanoparticles, $\mathrm{Al}_{2} \mathrm{O}_{3}$ and $\mathrm{TiO}_{2}$, with a primary size in the range of $40-60 \mathrm{~nm}$ to Enhance Oil Recovery (EOR). Nanofluids were prepared by dispersing $0.05 \mathrm{wt} \%$ metal-oxide nanoparticles with synthetic saline water. Berea sandstones core samples were used as porous media with average porosity and permeability of $15 \%$ and 60 md respectively. The viscosity of the degassed 


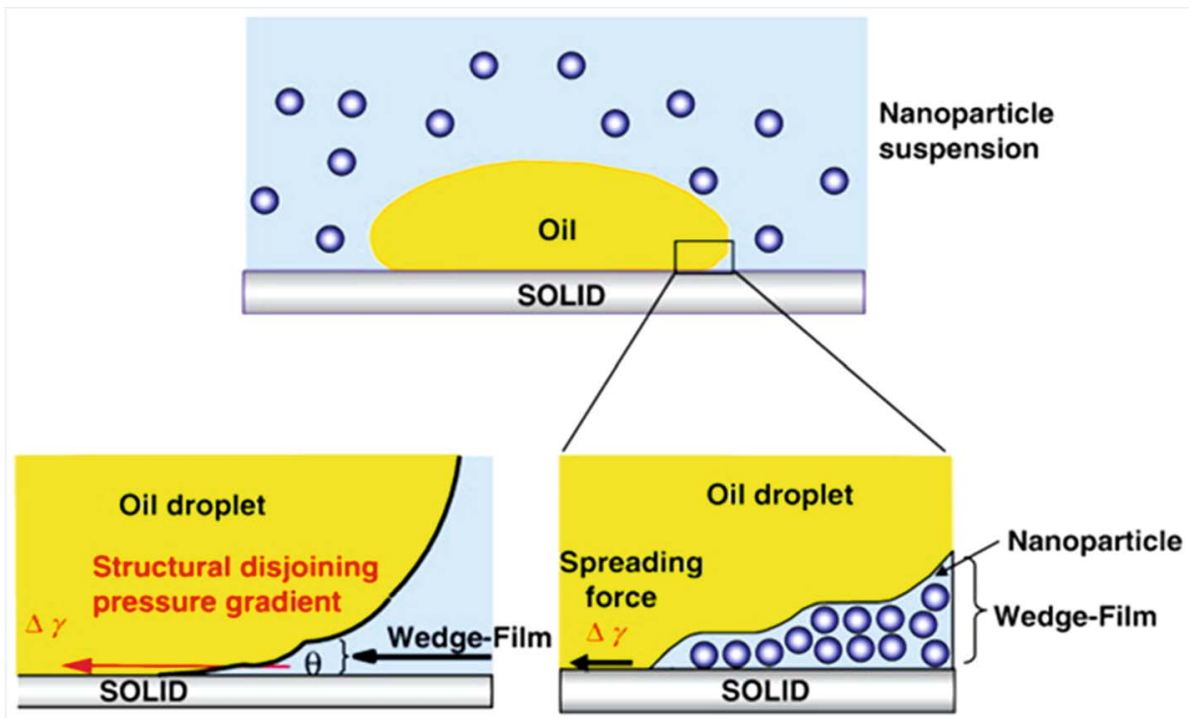

Fig. 1. Nanoparticle structuring in the wedge-film resulting in structural disjoining pressure gradient at the wedge vertex (from Wasan et al., 2011).

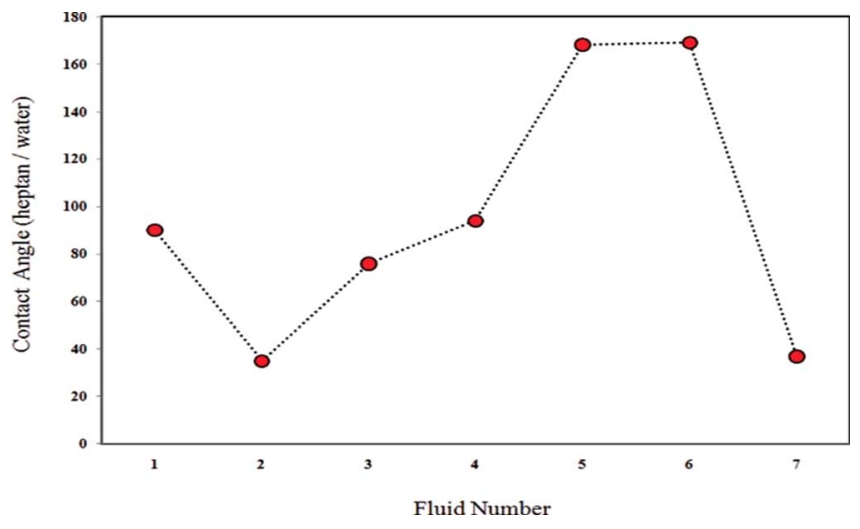

Fig. 2. Measured $n$-heptane/water contact angle of the oil-wet carbonate rocks aged in different nanofluids (from Karimi et al., 2012).

crude oil ranged from 5 to $50 \mathrm{cp}$. The results showed that metal oxides altered the wettability to more water-wet (the contact angle decreased from 54 to $21^{\circ}$ ) and enhanced the oil recovery (about 24\% higher) more than the nonmetal oxides. Hendraningrat and Torsaeter (2014) also found that the stability of the nanofluids could be improved by using a dispersant such as Povidone. They did not present any change of IFT by the addition of nanoparticles.

Nazari Moghaddam et al. (2015) investigated the performances of eight different nanoparticles for wettability alteration from oil- to water-wetness in carbonate rocks. The core flooding results showed an increase, about $8-9 \%$, in oil recovery by injecting the nanofluids with $\mathrm{CaCO}_{3}$ and $\mathrm{SiO}_{2}$ nanoparticles of 35-40 nm.

Nwidee et al. (2017) investigated the influence of zirconium (IV) oxide $\left(\mathrm{ZrO}_{2}\right)$ and nickel (II) oxide (NiO) nanoparticles on the wetting preference of fractured limestone (oil-wet). $\mathrm{ZrO}_{2}$ demonstrated a better efficiency by altering strongly oil-wet $\left(\theta=152^{\circ}\right)$ calcite substrates into a strongly water-wet $\left(\theta=44^{\circ}\right)$ state, $\mathrm{NiO}$ changed wettability to an intermediate wet condition $\left(\theta=86^{\circ}\right)$ at $0.05 \mathrm{wt} \%$ nanoparticle concentration. The contact angles decrease with the increase in nanoparticle concentration (Fig. 7a), time (Fig. 7b), and salinity (Fig. 7c) in a continuous trend, especially at suitable nanoparticle concentrations $(0.004-0.05 \mathrm{wt} \%)$.

Nwidee et al. (2017) found that nanoparticles adsorbed on the surface of the calcite crystals, as shown in Figure 8, might have promoted the oil displacement.

Note that the oil-wetness of the calcite crystals used by Nwidee et al. (2017) was rendered using Dodecyltriethoxysilane (C18H40O3Si), which might have an issue of wettability steadiness.

Surfactant or surfactant-like chemicals were used in the nanofluids along with nanoparticles in many reports that claimed wettability alteration (Karimi et al., 2012; Zhang et al., 2014a). However, it is well-known that many types of surfactants are able to change the rock wettability. Such studies may not provide clear and conclusive evidence on wettability alteration using nanoparticles when control experiments are not conducted. According to the previous discussion, however, there is convincing evidence that shows the addition of nanoparticles could alter the wettability from oil- to water-wetness.

In order to avoid the above problems caused by the addition of surfactants into nanofluids, Jiang et al. (2017) investigated the effect of nanoparticles addition on the wettability and oil recovery without adding any other chemicals other than silica nanoparticles into the nanofluid. They found that bare silica nanoparticles had an impact on wettability. An increase in nanofluid concentration and a decrease in nanoparticle size both result in a decrease in contact angle (makes the substrate more water-wet), which increase the oil recovery by about $8.7 \%$. Jiang et al. (2017) reported that bare silica nanoparticles had no influence on IFT between $n$-decane and nanofluid. 


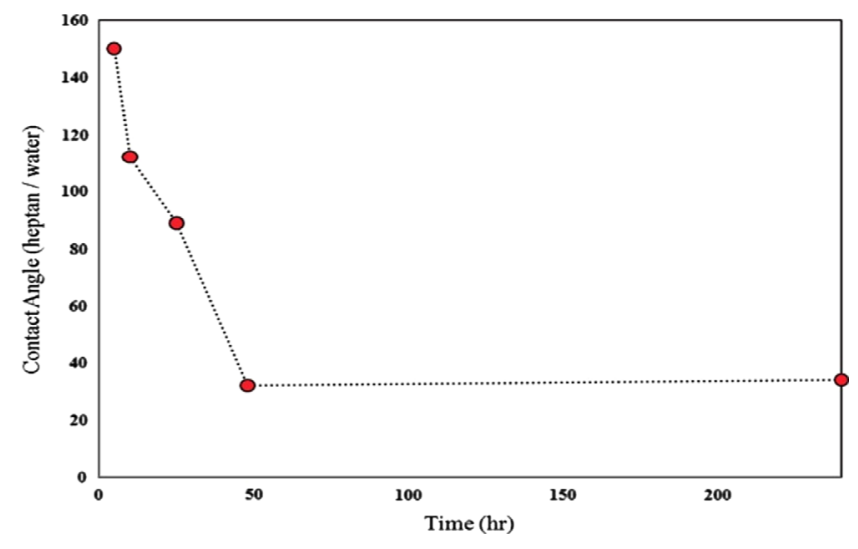

Fig. 3. Effect of the aging time on the wettability of carbonate plates aged in Fluid 2 as measured by $n$-heptane/water contact angle (from Karimi et al., 2012).

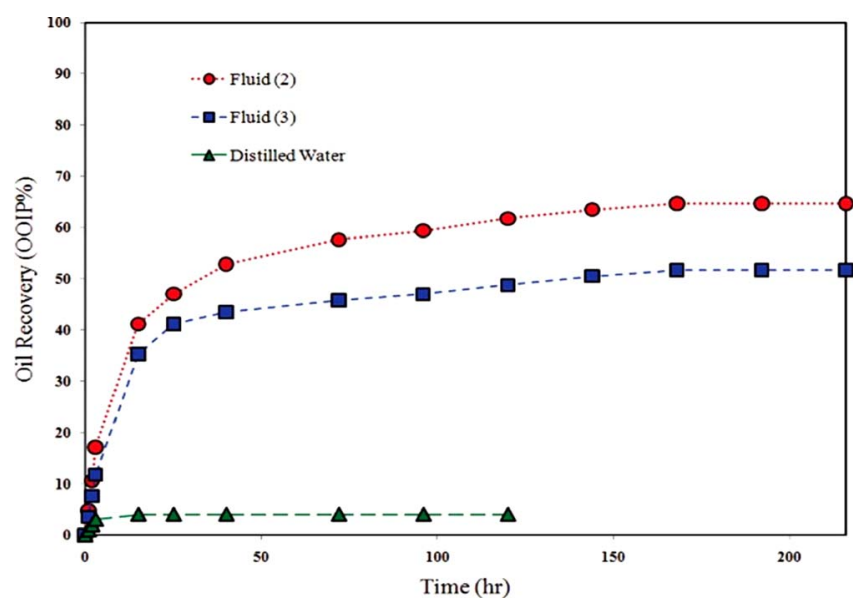

Fig. 4. Spontaneous imbibitions of Fluids 2 and 3 into oil-wet cores at $70{ }^{\circ} \mathrm{C}$ (from Karimi et al., 2012).

\subsection{Reduction in IFT}

Many papers have reported that the addition of nanoparticles could reduce IFT (Suleimanov et al., 2011; Zhang et al., 2014a; Moradi et al., 2015; Hu et al., 2016; Sharma et al., 2016) but none reported that the reduction in IFT is the only mechanism for EOR by nanofluids. In almost all of the cases, wettability has been altered if IFT was reduced, not the other way around though. For example, Suleimanov et al. (2011) reported a 70-90\% reduction in interfacial tension of oil/water system in comparison with surface-active agent aqueous by using nanofluid. Zhang et al. (2014a) observed a $91 \%$ reduction in IFT (16-1.4 dynes/cm) by using nanofluid. These experimental results will be discussed in more detail in the Section 1.8 because reduction in IFT is often associated with other mechanisms for nanofluid EOR. a)

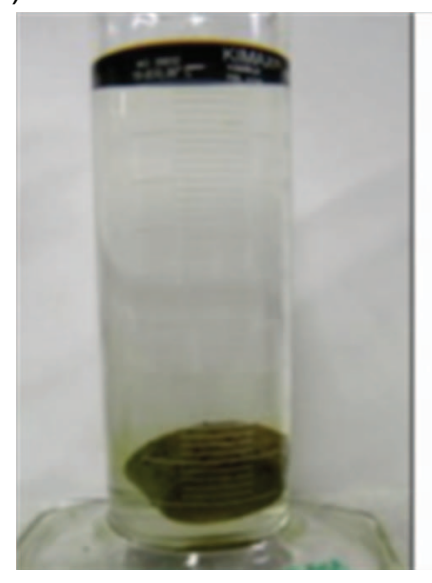

b)

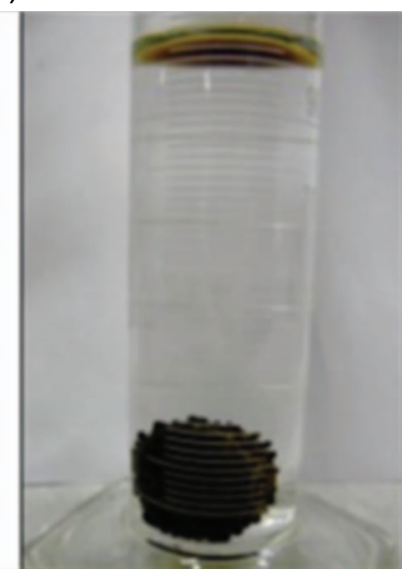

Fig. 5. Comparison of $10 \%$ nanoparticle in $2 \% \mathrm{KCl}$ (a) vs. a $2 \%$ $\mathrm{KCl}$ control with Berea sandstone (b) after $48 \mathrm{~h}$ at ambient conditions (from Mcelfresh et al., 2012).

\subsection{Increase in the viscosity of aqueous solution}

A few papers have reported the increase in the viscosity of aqueous solution because of the addition of nanoparticles. Suleimanov et al. (2011) found about 100\% increase in the viscosity of aqueous solution, from 1.0 to about $2 \mathrm{cp}$ by adding $0.001 \%$ wt nanoparticles (nonferrous metal) to the sulphanole solution.

Sharma et al. (2016) observed the increase in the viscosity of both nanofluids with polymer (nanoparticle) and Nanofluids with Surfactant-Polymer (NSP) by a factor of about three by introducing $1.0 \mathrm{wt} \%$ silica nanoparticles, compared with that of polymer and SP (surfactant-polymer) solutions. More details regarding this phenomenon will be discussed in Section 2.8.

Verga et al. (2017) reported that core-shell nanoparticle technology can be highly beneficial to improve the effectiveness of waterflooding interventions when the presence of different permeability zones strongly affects oil displacement. One of the possible mechanisms might be the increase in water viscosity by injecting a water dispersion of nanocapsules through gelation or aggregation.

\subsection{Decrease in oil viscosity}

Ogolo et al. (2012) reported that the addition of aluminium oxide nanoparticles could EOR by about $12 \%$ in a sand pack. One of the mechanisms they speculated was that $\mathrm{Al}_{2} \mathrm{O}_{3}$ had the ability to reduce oil viscosity. However, they did not provide any data on the reduction of oil viscosity. The speculation was based on the observation that aluminium oxide is a good catalyst for upgrading heavy oil (Nares et al., 2007). Ogolo et al. (2012) also found that some of the nanoparticles could reduce rock permeability or change wettability in the undesired direction and then decrease, instead of increase, oil recovery in many cases. Kashefi et al. (2018) reported similar observation that the addition of zeolite beta nanoparticles into crude oil could reduce rock permeability of a sand pack. 


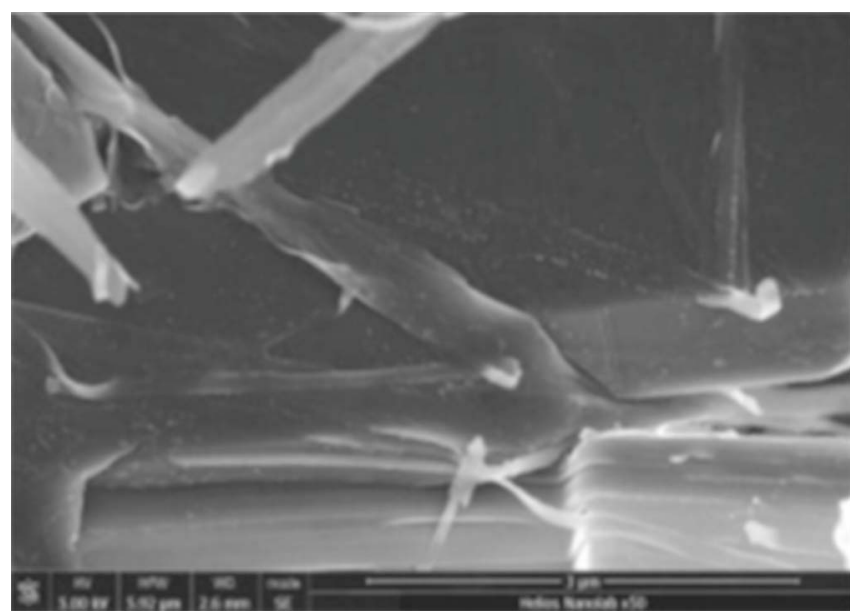

Fig. 6. Adsorption of nanoparticles at interfaces in Codell core flow study (from Mcelfresh et al., 2012).

Note that it should be careful to use nanoparticles if crude oil contains high content of asphaltene. Rezakazemi et al. (2017) observed that the addition of aluminium oxide nanoparticles into crude oil had increased the asphaltene molecular size significantly.

\subsection{Change in disjoining pressure}

Currently observed EOR phenomena by nanofluid containing nanoparticles may not be fully explained using the existing theories. Kondiparty et al. (2012) reported that there are two contact lines (Fig. 9) instead of one in the case where an oil droplet on a surface immersed in a solution with nanoparticles. On the other hand, traditional mechanisms cannot account accurately for the faster spreading of a nanoparticle solution on a surface for higher nanoparticle concentrations and higher viscosities. It is observed that the inner and outer contact lines move with a constant spreading velocity, which is a function of salt concentration, bulk volume fraction of nanoparticles, size, and polydispersity of nanoparticles, as well as IFT between the drop and the spreading phase (Chengara et al., 2004; Kondiparty et al., 2012).

Many have investigated the effect of disjoining pressure gradients on spreading and wettability. However, the characterization is different. De Gennes (1985) proposed that the components of disjoining pressure are van der Waals' forces alone while Hirasaki (1991) considered as a combination of van der Waals' and electrostatic forces. The above Conventional Disjoining Pressure (CDP) is a result of the London - van der Waals force that has a short-range nature.

Differently, Wasan and Nikolov (2003) suggested the concept of Structural Disjoining Pressure (SDP), a force normal to the interface, that has a long-range nature. Wasan and Nikolov (2003) have demonstrated that structural disjoining pressure is generated from the ordering and structuring of nanoparticles in a confined wedge (Fig. 1). The effect of structural disjoining pressure may extend to a film depth of a few nanoparticle diameters
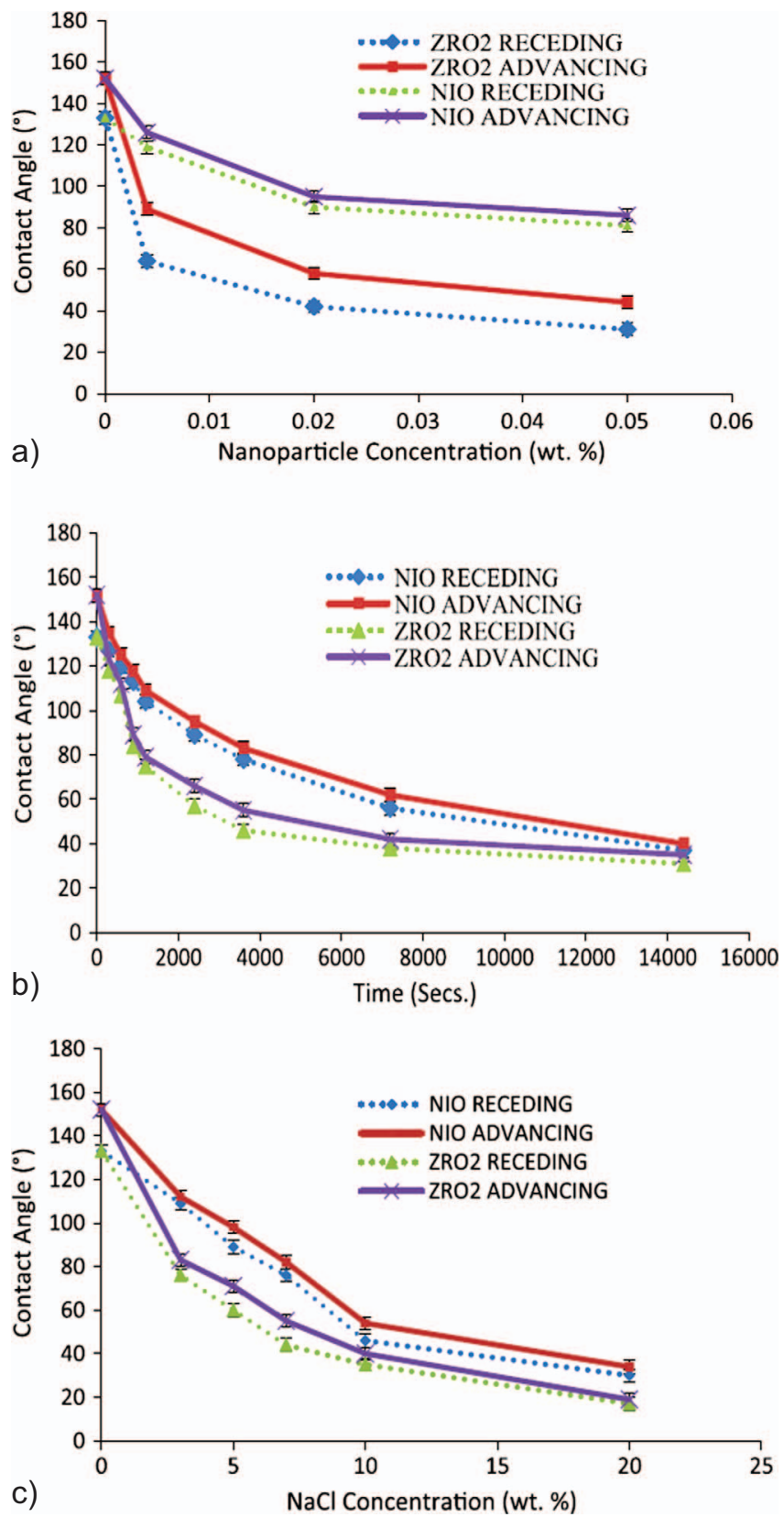

Fig. 7. contact angles decrease with the increase in time, nanoparticle concentration and salinity (from Nwidee et al., 2017). a: Receding and advancing water contact angles (versus toluene) as a function of nanoparticle concentration (60 min exposure time). b: Receding and advancing water contact angles (versus toluene) as a function of time ( $7 \mathrm{wt} \% \mathrm{NaCl}$ brine; 0.05 wt\% nanoparticle concentration). c: Receding and advancing water contact angles (versus toluene) as a function of $\mathrm{NaCl}$ concentration (0.05 wt\% nanoparticle concentration; $60 \mathrm{~min}$ exposure time).

(long-range). The origin of structural disjoining pressure is the confinement of the nanoparticles in the wedge region as opposed to the greater freedom of location for the nanoparticles in the bulk liquid. The layering and structuring arrangement of the nanoparticles causes an excess pressure in the film, i.e., the structural disjoining pressure. 
a)
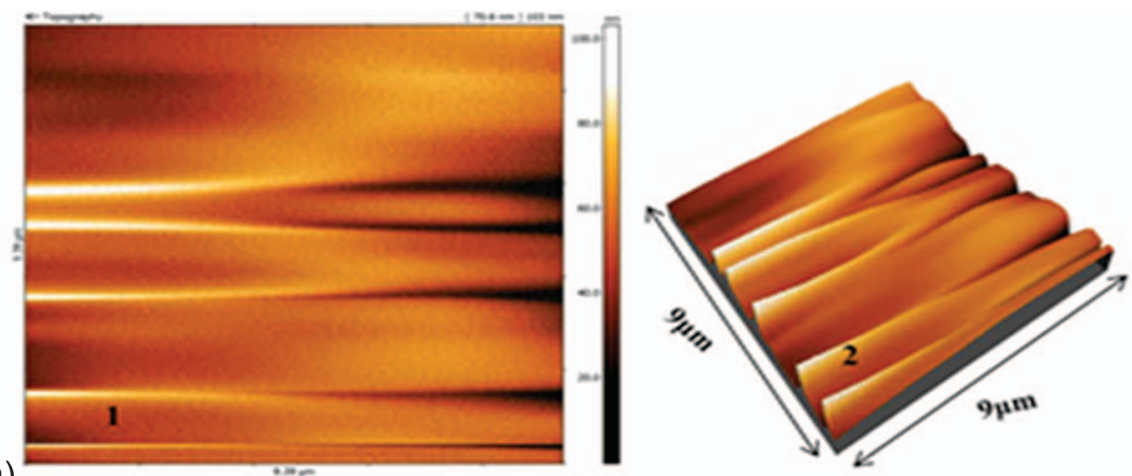

b)
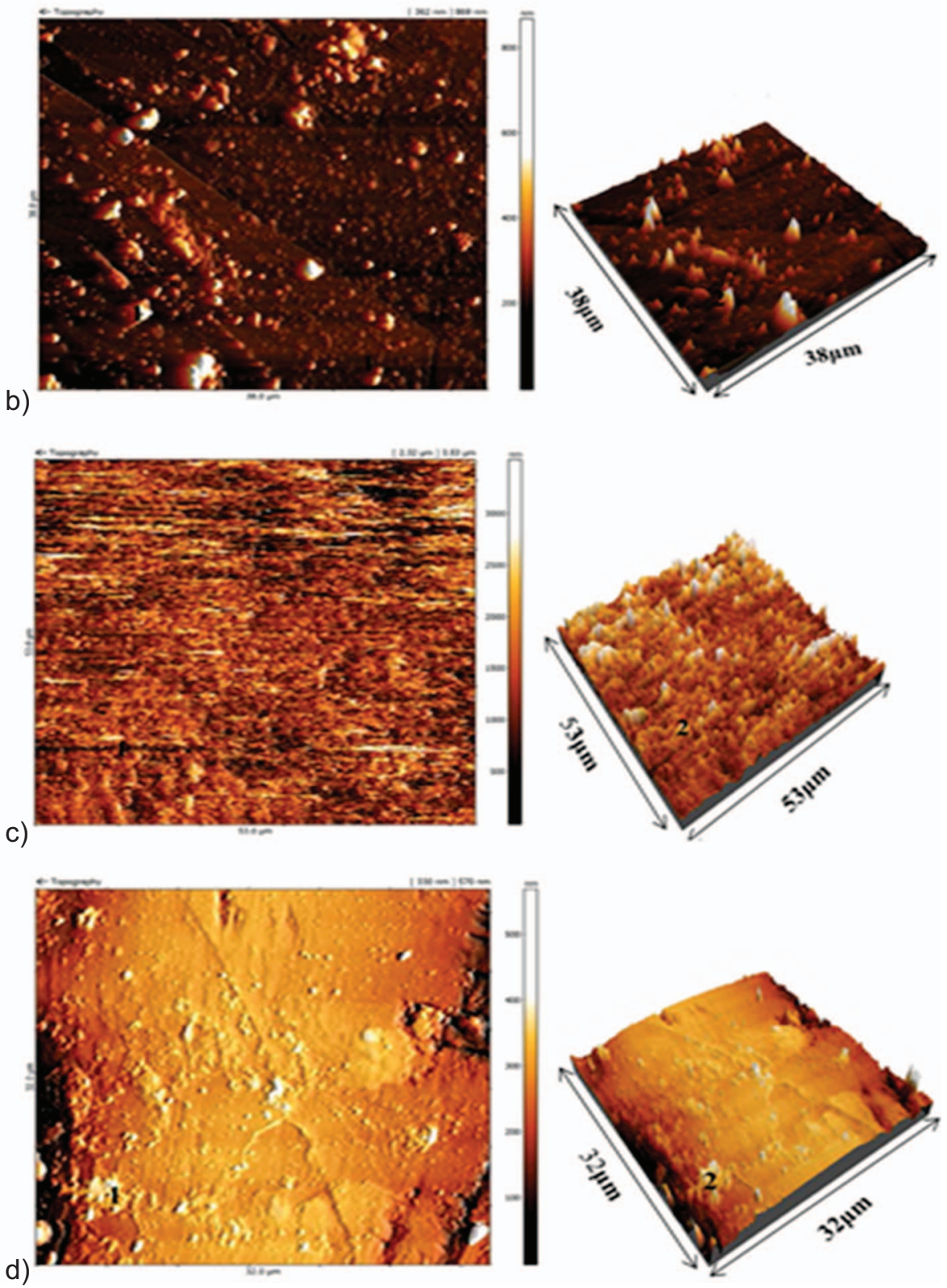

Fig. 8. AFM height images of calcite crystals: a) Untreated calcite; b) Silane treated calcite; c) $\mathrm{ZrO}_{2}$ modified; d) NiO modified (Nwidee et al., 2017). The different colors indicate variation in height of the surface with high Z-values (higher features appearing as white) and low $Z$-values (lower features appearing as dark shades). 


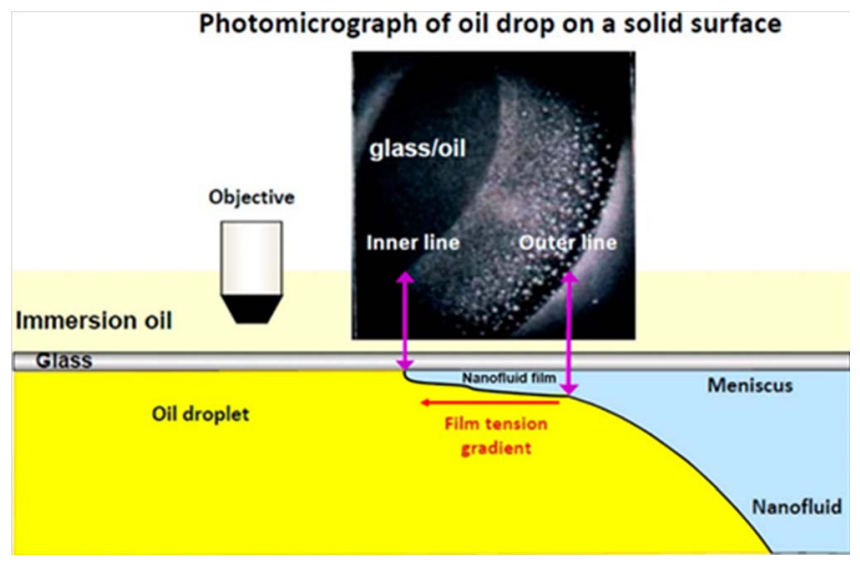

Fig. 9. Photomicrograph taken by reflected-light interferometry depicting the nanofluid structural disjoining pressure on oil displacement dynamics. The "outer line" is the macroscopic three-phase contact line, and the "inner line" depicts the advancing nanofluid film driven by structural disjoining pressure (from Kondiparty et al., 2012).

The formulated nanofluid may have a high osmotic pressure (e.g., higher than about $200 \mathrm{~Pa}$ for a $10 \mathrm{vol} \%$ nanofluid). Trokhymchuk et al. (2001) developed an analytical expression for the SDP $\left(\Pi_{\mathrm{st}}\right)$ based on a solution of the Ornstein-Zernike statistical mechanics equation:

$\Pi_{\mathrm{st}}(h)=-P, 0<h<d$

$\Pi_{\mathrm{st}}(h)=\Pi_{0} \cos \left(\omega h+\varphi_{2}\right) e^{-\kappa h}+\Pi_{1} e^{-\delta(h-d)}, h>d$

where $d$ is the diameter of the nanoparticle, $h$ is the wedge film thickness and all other parameters $\left(\Pi_{0}, \Pi_{1}\right.$, $\left.\omega, \varphi_{2}, \kappa, \delta\right)$ in equation 2 are fitted as cubic polynomials in terms of the nanofluid volume fraction $(\phi) . P$ is the osmotic pressure, which is a function of the nanofluid volume fraction shown in equation 3 :

$$
P=\rho k T \frac{1+\phi+\phi^{2}-\phi^{3}}{(1-\phi)^{3}},
$$

where

$$
\phi=6 n_{\mathrm{p}} /\left(\pi d^{3}\right),
$$

here $n_{\mathrm{p}}$ is the number of particles per unit volume of the system.

As foreseen by equations $1-3$, the structural disjoining and osmotic pressures increase with the fraction of the nanoparticle volume. Nanofluid with a high osmotic pressure results in a high SDP. The details of the related mathematical models can be referred as to the paper by Chengara et al. (2004).

Wasan and Nikolov (2003) also demonstrated that SDP increases exponentially with a decrease in film thickness or number of nanoparticle layers between the solid and oil, as shown in Figure 10. It is the high SDP that enhances the spreading of the liquid phase (usually water) containing nanoparticles and can lead to wettability alteration from

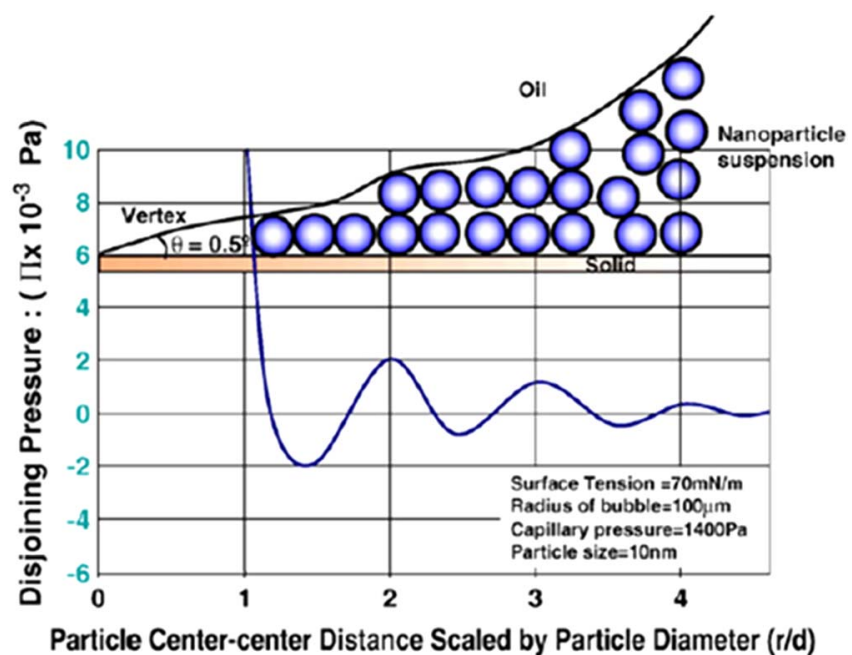

Fig. 10. Pressure on the walls of wedge for $0.5^{\circ}$ contact angle at the vertex as a function of radial distance (from Wasan and Nikolov, 2003).

oil- to water-wetness. Note that SDP has an oscillatory decay profile with the film thickness as shown in Figure 10.

Adjacent to the wedge-shape inner contact line, the nanoparticles can form ordered structures, as shown in Figure 10. The nanoparticle structuring phenomenon brings about the SDP in the wedge film with a higher disjoining pressure near the tip of the wedge than in the bulk meniscus. As a result, the oil-nanofluid interface moves forward with a progressive cleaving of the oil-solid contact and eventually detaches the oil drop. The SDP is dependent on the size, material, and other properties of the nanoparticles.

Chengara et al. (2004) examined the role of the structural component of SDP created by the confinement of nanoparticles, e.g., surfactant micelles in the wedge film of a spreading drop and further confirmed the long-range nature of SDP. The ordering of the nanoparticles is more important than the electrostatic and van der Waals' components in spreading. For the aspect of applications, Chengara et al. (2004) proposed that it is the normal force imbalance in SDP that displaces the oil from the solid surface, which is in contrast to the conventional theories that predict the removal of an oily pollutant as a result of the tangential (IFT) force imbalance at the contact line. Chengara et al. (2004) suggested that the ordering is a consequence of the increase in the system entropy. The ordered, solid-like structures near the contact lines lead to a very high disjoining pressure that causes a wedge-like spreading of the nanoparticle solution, resulting in two contact lines, as shown in Figure 9. Does the concept of SDP with a long-range nature, instead of a short-range nature, have consolidated theoretical basis? This may need be verified.

As pointed out by ShamsiJazeyi et al. (2014), SDP is just one of the components affecting disjoining pressure. Van der Waals, electrostatic, and solvation forces are other components that can affect the disjoining pressure too. In particular, electrostatics can be very effective in increasing the ability of wettability alteration by nanoparticles. If nanoparticles are coated with a polyelectrolyte, 


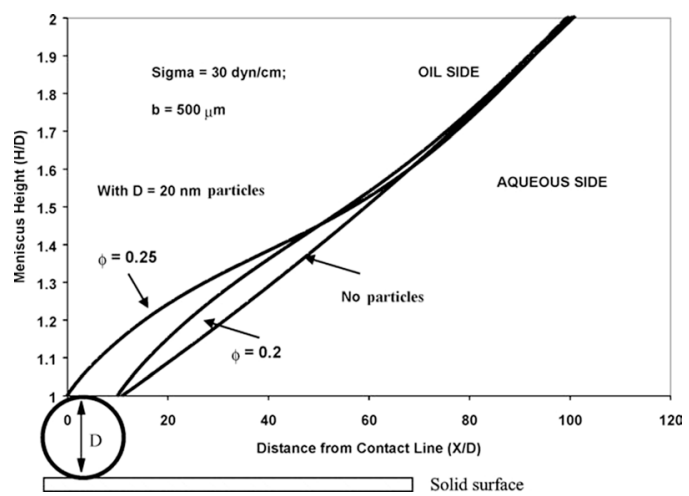

Fig. 11. Effect of nanoparticle volume fraction on meniscus profile (from Chengara et al., 2004).

electrostatic repulsive forces can increase the disjoining pressure and may cause significant increase in spreading of the phase containing the nanoparticles.

As discussed by Hu et al. (2016), a result of such a structure force SDP is that nanofluids could exhibit a good spreading capability in confined spaces. Such forces have been observed to have the following functions:

- to be able to change the macroscopic contact angle of a liquid droplet (Kim et al., 2007a, 2007b; Vafaei and Wen, 2010);

- to stabilize liquid films (Sethumadhavan et al., 2001);

- to lift an oil droplet from a wall in an aqueous solution (Hendraningrat et al., 2012; Nikolov and Wasan, 2014; Zhang et al., 2014b).

As shown by Nikolov and Wasan (2014), the SDP could be important for mobilizing individual oil droplets. However, the droplet form of oil might be unlikely in porous media during the process of nanofluid EOR.

Chengara et al. (2004) found that there is no appreciable change in the contact line position when the nanoparticle volume fraction is less than $20 \%$ in oil-water systems. This demonstrates that the effect of SDP on the removal of oil droplets is negligible in the cases where the nanoparticle volume fraction is less than $20 \%$ (Fig. 11).

Wen (2008) studied theoretically the influence of SDP on the nucleate boiling heat transfer of thermal nanofluids. The role of SDP was illustrated through a four-zoned microlayer evaporation model. The modeling results show that the alteration in wettability with concentration is nonlinear and is only significant at high nanoparticle concentrations $(>15 \%)$ in vapor-liquid systems, as shown in Figure 12.

The modeling results of SDP show that the increase in wettability with concentration is nonlinear and it only becomes important at high particle volume concentrations $(>15 \%$, Figs. 11 and 12). If this is true, while the local nanoparticle concentration increases, the increase in the viscosity of the confined nanofluid could become significant and should be considered as one of the mechanisms for EOR by nanofluid. Another concern is that the modeling

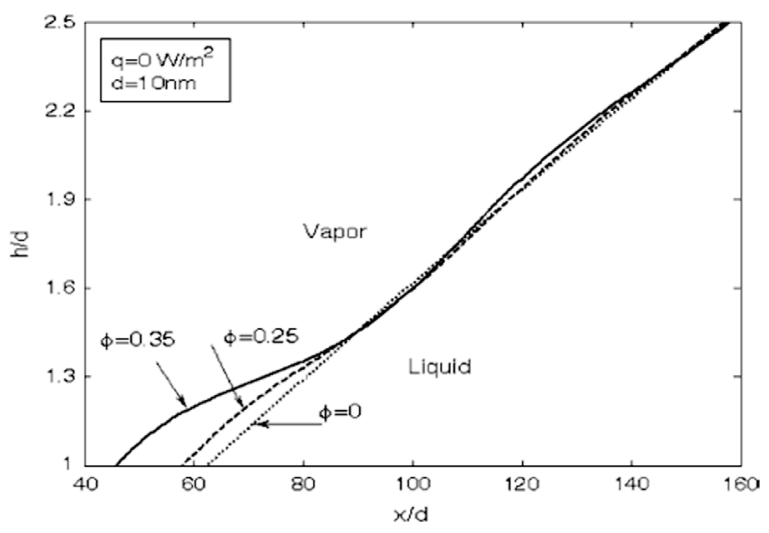

Fig. 12. The influence of the nanoparticle concentration on the interfacial shape (from Wen, 2008).

was based on the steady state, and only the equilibrium shape of the meniscus under the action of an oscillatory SDP was calculated.

On the other hand, if these modeling data were generally true, SDP may not be very important for EOR, although nanoparticles have a tendency to migrate into the microlayer to form ordered and structured solid-like layers. This is because most of the nanofluid EOR experiments reported in the literature were conducted using very dilute nanofluids with typical concentrations of nanoparticles below $1 \%$ in weight. For example, Hu et al. (2016) used a concentration of 10-500 ppm and Luo et al. (2016) prepared the nanofluid with $0.01 \%$ nanoparticles. Considering this, SDP may not be the mechanism of nanofluid EOR. Note that Hu et al. (2016) did not suggest SDP as one of the mechanisms for nanofluid EOR.

However, it should be noted that the modeling results reported by Wen (2008) were obtained under specific conditions. The conclusion that the change in wettability is only significant at high nanoparticle concentrations $(>15 \%)$ may not be true in other cases with different conditions. Wen (2008) has also made several assumptions for the modeling. So it is difficult to verify that the above conclusion is general and adaptable for the nanofluid EOR.

\subsection{Climbing film and slug-like displacement}

Luo et al. (2016) designed and produced a nanofluid of graphene-based amphiphilic nanosheets that is very effective at low concentration for EOR. They found that the unmodified graphene oxide precipitated while the interfacial film of the nanosheets remained intact after settling for $2 \mathrm{~h}$, as shown in Figure 13.

Luo et al. (2016) observed that a climbing film appeared and grew at moderate hydrodynamic conditions to encapsulate the oil phase. With strong hydrodynamic energy input, a solid-like interfacial film could be formed and was able to return to its original form even after being seriously disturbed. The film rapidly and efficiently separated oil and water phases into slug-like oil displacement. The unique behavior of the nanofluid with nanosheets improved the oil recovery from 6.7 to $15.2 \%$, depending on the rock properties probably. The EOR data in different artificially-made 


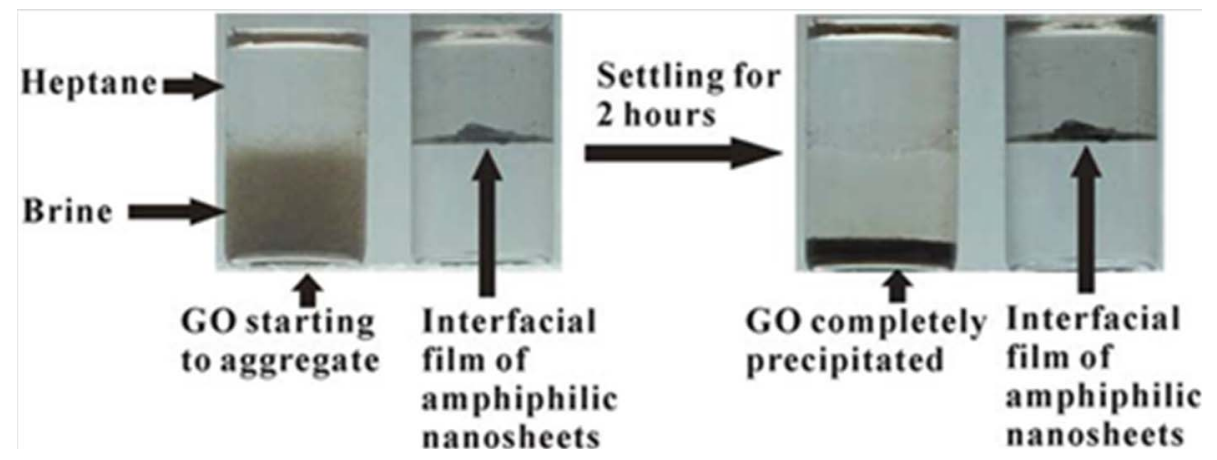

Fig. 13. Behaviors of unmodified graphene oxide (GO) and amphiphilic nanosheets in the heptane/brine system. Small pieces of interfacial film were attached to the hydrophilic glass surface in the heptane phase due to its amphiphilicity, which appeared as black dots (Luo et al., 2016).

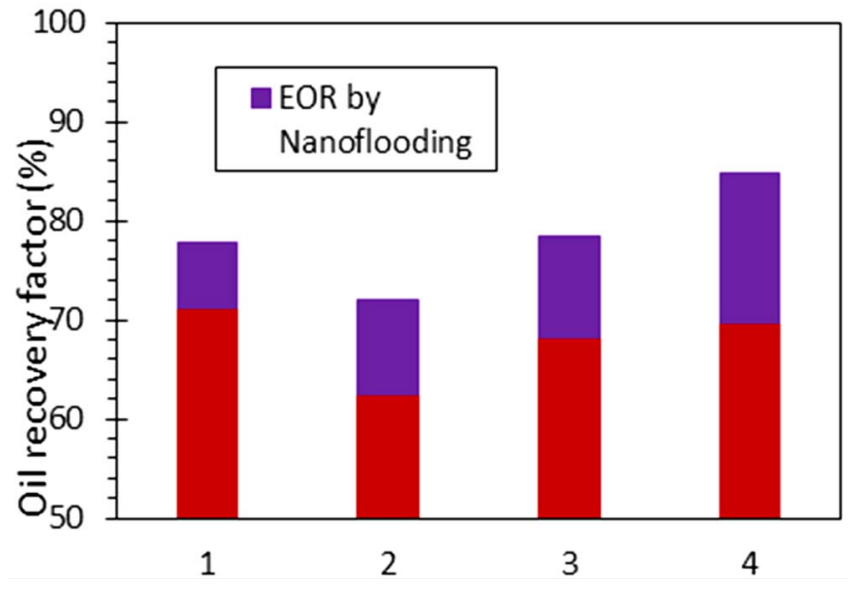

Fig. 14. The EOR data in different artificially-made rock samples (from Luo et al., 2016).

rock samples are shown in Figure 14. It would be interesting if Luo et al. (2016) provided the oil recovery data at different flooding time or injected pore volume.

Luo et al. (2016) mentioned that the nanosheets spontaneously approached the oil-water interface and reduced the IFT in a saline environment $(4 \mathrm{wt} \% \mathrm{NaCl}$ and $1 \mathrm{wt} \%$ $\mathrm{CaCl}_{2}$ ), regardless of the solid surface wettability. This may be reasonable because the surface of the nanosheets has been modified to amphiphilic. Unfortunately, they have not provided the IFT data after adding the graphene-based amphiphilic Janus nanosheets which have two different compositions distinctly compartmentalized on the surfaces.

For such a high oil recovery enhanced by nanofluid, Luo et al. (2016) proposed two oil displacement mechanisms, as illustrated in Figure 15:

- climbing film (a film of nanosheets along the solid surface) encapsulation for water-wet surface. As shown in Figure $15 \mathrm{a}$, at $t=t_{0}$ the concentration of nanosheets at the oil-water interface increase because of adsorption and produces the concentration gradient leading to the transfer of the nanosheets to the three-phase (nanofluid, oil, and rock solid) region, detaching and encapsulating oil from the rock surface. When flow continues under hydrodynamic condition from $t_{0}$ to $t_{0}+\Delta t$, the film grows due to the ongoing supply of nanosheets from the nanofluid and carries the oil phase forward;

- slug-like displacement by the interfacial film. As seen in Figure 15b, an elastic interfacial film forms at the oilwater interface at strong hydrodynamic power condition at $t=t_{0}$. The film can resist bending and also reform after being disrupted. As a result, the oil interface is slug-like and displaced over a certain distance at $t=t_{0}+\Delta t$.

The nanosheets spontaneously approached the oilwater interface and reduced the IFT in a saline environment $\left(4 \mathrm{wt} \% \mathrm{NaCl}\right.$ and $\left.1 \mathrm{wt} \% \mathrm{CaCl}_{2}\right)$, regardless of the solid surface wettability. Unfortunately, Luo et al. (2016) did not present the data of IFT of their oil-nanofluid systems.

If one looks at Figures 15a and 15b, it might be considered that the wettability of the system was altered from water- to neutral-wetness. One question arises: can the mechanism for EOR by the nanosheets be categorized as wettability alteration instead of climbing film and slug-like displacement by the interfacial film?

Luo et al. (2016) claimed that the unique behavior of their nanosheet nanofluid tripled the best performance of conventional nanofluid flooding methods under similar conditions, i.e., under similar conditions (0.01\% nanofluid concentration), their recovery was $15.2 \%$, more than triple the best reported result of $4.7 \%$. Suleimanov et al. (2011), however, reported an experimental study of nanofluids and the enhanced oil recovery was $12-17 \%$ under the nanoparticle concentration of $0.001 \%$. El-Diasty and Aly (2015) also observed high incremental oil recovery, $26.4 \%$, using the nanoparticle concentration of $0.01 \%$ and the nanoparticle size of $20 \mathrm{~nm}$. These two papers were not cited by Luo et al. (2016). Hu et al. (2016) reported a much higher increase of oil recovery $(31.4 \%)$ at breakthrough with a much lower nanoparticle concentration (10-500 ppm, rutile ellipsoid $\mathrm{TiO}_{2}$ nanoparticles). 
a)
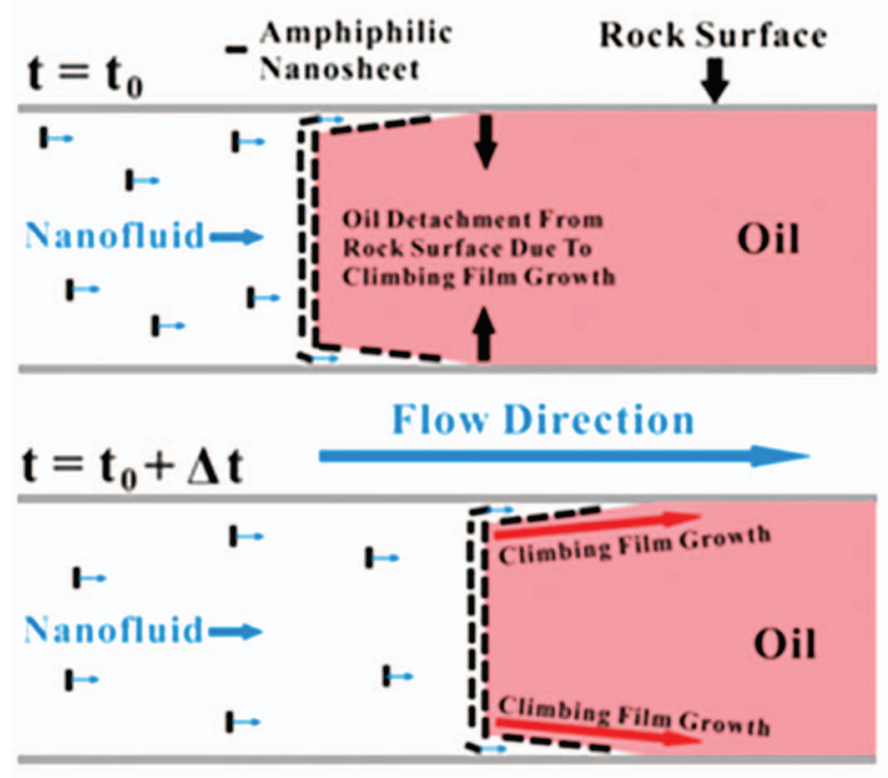

b)
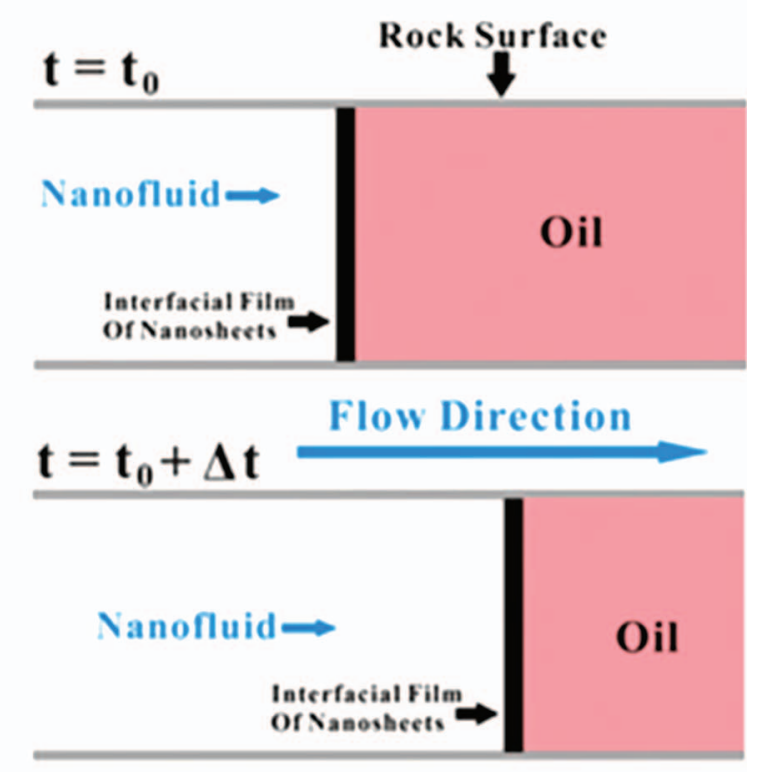

Fig. 15. Schematic illustration of oil displacement mechanisms. a: Climbing film encapsulation mechanism for water-wet surface. b: Slug-like displacement mechanism (from Luo et al., 2016).

\subsection{Log-jamming effect}

Log-jamming is the blockage of pore throats that are larger than each nanoparticle, which is the same mechanism as mechanical entrapment, but it is more complex. The flow velocity at pore throats is usually greater than that at pore bodies because of the size difference between pore throats (smaller diameters) and bodies (greater diameters). On the other hand, the water phase may flow more rapidly than the nanoparticles or particles that are heavier than water at the entrance of a pore throat. This will bring about the accumulation of nanoparticles at the pore throat entrance. The pore throat radius will then be reduced gradually and eventually may be blocked. Particles may block pores larger than the particle size due to log-jamming effect. The main factors governing the log-jamming are the size, concentration of the nanoparticles, pore size distribution of the porous media, and the flow rate (Bolandtaba et al., 2009; Skauge et al., 2010; El-Diasty and Aly, 2015).

Alaskar (2013) observed the log-jamming phenomenon visually using a micromodel (Fig. 16). This image also shows the particles flowing through the surrounding grains and plugging small pore throats with radii much greater than those of the particles.

For oil-water two-phase flow, the nanoparticles can accumulate at the entrance of pore throats during water flooding with nanofluid. This accumulation of nanoparticles may bring about a higher pressure in the adjacent pores. The oil trapped in those pores will be mobilized by the higher pressure and can then be produced. Many have observed the log-jamming effect in the EOR experiments using nanofluids (Bolandtaba et al., 2009; Skauge et al., 2010; El-Diasty and Aly, 2015; Hu et al., 2016).

El-Diasty and Aly (2015) studied the effects of nanoparticle concentration and size on oil recovery using Bahariya sandstone sample with a porosity of $26 \%$ and a permeability of $378.73 \mathrm{md}$. They found that the incremental oil recovery due to nanofluid injection increased with the nanoparticle concentration in the range from 0.01 to $3.0 \%$ wt but had the maximum value with nanoparticle size of $20 \mathrm{~nm}$. Remarkably the oil recovery increased from $44.6 \%$ by base water flooding (nanoparticle concentration was $0.0 \%$ ) to $71 \%$ by nanofluid with nanoparticle $(20 \mathrm{~nm})$ concentration of only $0.01 \%$ wt. The incremental oil recovery was about $26.4 \%$. Note that the incremental oil recovery was about $8 \%$ when nanoparticle $(20 \mathrm{~nm})$ concentration increased from 0.01 to $3.0 \%$ wt. It is not clear if there were any other chemicals in the nanofluid.

\subsection{Combination of different mechanisms}

Many researchers found that more than one mechanism is associated with nanofluid EOR. Suleimanov et al. (2011) reported an experimental study of nanofluids for enhanced oil recovery. An aqueous solution of anionic surface-active agents (Sodium 4-alkyl-2ylbenzenesulfonate) with the addition of light nonferrous metal nanoparticles was used. The size of nanoparticle ranged from 70 to $150 \mathrm{~nm}$ with a density of $0.32-0.37 \mathrm{~g} / \mathrm{cm}^{3}$. They did not identify the material of the nanoparticles. The concentration of nanoparticles was $0.001 \%$ mass. Suleimanov et al. (2011) demonstrated that the use of the nanofluid resulted in a $70-90 \%$ reduction in IFT of oil/water system in comparison with surface-active agent aqueous. They found that the addition of nanoparticles to the sulphanole solution did not change the wettability considerably. The contact angle decreased from 23 to $19^{\circ}$. The difference was only $4^{\circ}$. They also observed that the addition of nanoparticles to the sulphanole solution increased the viscosity of aqueous solution about $100 \%$, from 1.0 to about $2 \mathrm{cp}$. The viscosity of 


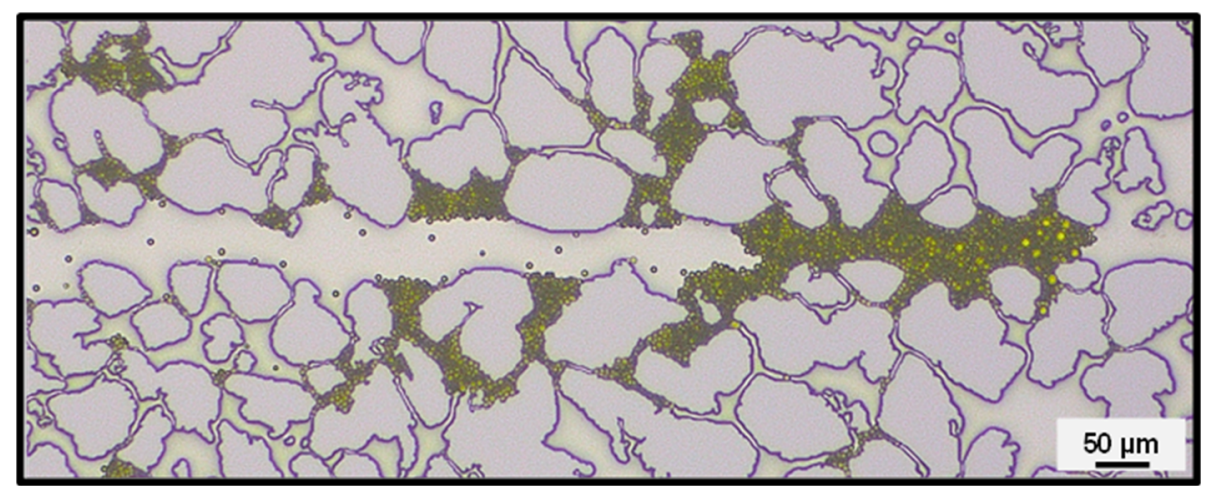

Fig. 16. An optical image showing the plugging of the $25 \mu \mathrm{m}$ fracture (Micromodel B1) by the smaller particles of the polydisperse sample (from Alaskar, 2013).

the oil phase was $7 \mathrm{cp}$ but the type of oil was not clarified. The increase in oil recovery was significant, about $12 \%$. They also observed that the adsorption of sulphanole and the surfactant increased 14.5 and 18.5 times respectively by the addition of nanoparticles. The adsorption process was also more stable compared with the cases without nanoparticles.

Hendraningrat et al. (2013) found that the hydrophilic silica nanoparticles have the ability to reduce the IFT between oil-aqueous system and the contact angle of the aqueous phase. The IFT and contact angle decrease when nanofluid concentration increases. Additional recovery, however, might not be guaranteed despite increasing nanofluid concentration could decrease IFT and alter wettability.

Zhang et al. (2014a) conducted spontaneous imbibition tests in Berea sandstone (water-wet) and single-glass capillaries using a reservoir crude oil with a viscosity of $24.58 \mathrm{cp}$ at $50{ }^{\circ} \mathrm{C}$ and a reservoir brine solution with a high salinity and a suitable nanofluid. A $40 \mathrm{wt} \%$ colloidal dispersion of silicon (IV) oxide in water was diluted with DeIonized (DI) water to prepare the $10 \mathrm{vol} \%$ silica nanofluid. The nanoparticles had a nominal (geometric) diameter of $20 \mathrm{~nm}$, with a density of $1.15 \mathrm{~g} / \mathrm{cm}^{3}$ and $\mathrm{pH}$ of 9.7 . No details about the chemical compositions and properties of the nanofluid were specified. They reported that the nanofluid had a 91\% (16-1.4 dynes/cm) reduction in IFT and a $98 \%$ decrease in contact angle $\left(74-1.2^{\circ}\right)$ in oil/water systems. The significant reduction in both IFT and contact angle resulted in an efficiency of $50 \%$ for Berea sandstone, compared to only $2 \%$ recovered with the $\mathrm{pH} 9.7 \mathrm{DI}$ water and an increase of oil recovery in about $30 \%$, compared to $17 \%$ using the brine alone at a reservoir temperature of $55^{\circ} \mathrm{C}$. The experimental data by spontaneous imbibition are shown in Figure 17.

Zhang et al. (2014a) stated: ".......As time goes on, the rate of the crude oil displacement decreases and reaches the equilibrium stage at which the buoyancy force equals the capillary force plus friction force, causing the oil displacement process to stop". Actually capillary force was the driving force because the glass tube was water-wet and had the same direction of buoyancy force instead of the direction as shown in Figure 15 in their paper. In the same figure, the oil/water interface should be concave upward instead of downward.

Esfandyari Bayat et al. (2014) evaluated the impact of three metal oxide nanoparticles, $\mathrm{Al}_{2} \mathrm{O}_{3}(40 \mathrm{~nm}), \mathrm{TiO}_{2}$ (10-30 nm), and $\mathrm{SiO}_{2}(20 \mathrm{~nm})$, on EOR through a limestone sample at different temperatures. When the nanofluids were introduced to porous media, Esfandyari Bayat et al. (2014) found that nanoparticles influenced the immobile oil droplets through wettability alteration, reduction of IFT and oil viscosity. The experimental results are depicted as follows (Fig. 18).

Figure 19 shows significant reduction in IFT at different temperatures by the addition of nanoparticles in brine without any surfactant-like chemicals, as reported by Esfandyari Bayat et al. (2014). Note that there have been few experimental data like these measured in oil/water to demonstrate substantial reduction in IFT by the addition of nanoparticles in pure water (without any surfactant-like chemicals).

The reduction in the viscosity of the produced crude oil is not very noteworthy at low temperature but is more prominent at higher temperature, as shown in Figure 20. This might be because the catalyst effect of the metal nanoparticles is more significant at high temperatures.

Compared with $\mathrm{TiO}_{2}$ and $\mathrm{SiO}_{2}, \mathrm{Al}_{2} \mathrm{O}_{3}$ was the best nanoparticle in terms of EOR through limestone porous media at all temperatures as shown in Figure 21.

Moradi et al. (2015) investigated the effect of adding nanoparticles in the aqueous phase on the efficiency of WAG (Water Alternating Gas) EOR process. Silica nanopowder $\left(\mathrm{SiO}_{2}\right)$ with a particle size of $11-14 \mathrm{~nm}$ was used to prepare the $0.1 \mathrm{wt} \%$ water-based nanofluid. WAG experiments were conducted in carbonate rock samples with a porosity of $10.33 \%$ and a permeability of $2.839 \mathrm{md}$ using medium crude oil with a viscosity of $30.3 \mathrm{cp}$ at $60^{\circ} \mathrm{F}$. They found that the addition of the nanoparticles caused a $21 \%$ (13.62-10.69 dynes/cm) reduction in IFT and an $87 \%$ decrease in contact angle $\left(122-16^{\circ}\right)$ of oil/water systems. The experimental results demonstrated over $20 \%$ increment in oil recovery by nano-WAG process in comparison to the conventional WAG process, as shown in Figure 22.

Sharma et al. (2016) investigated the effect of silica nanofluids with polymer (P) and surfactant (sodium 

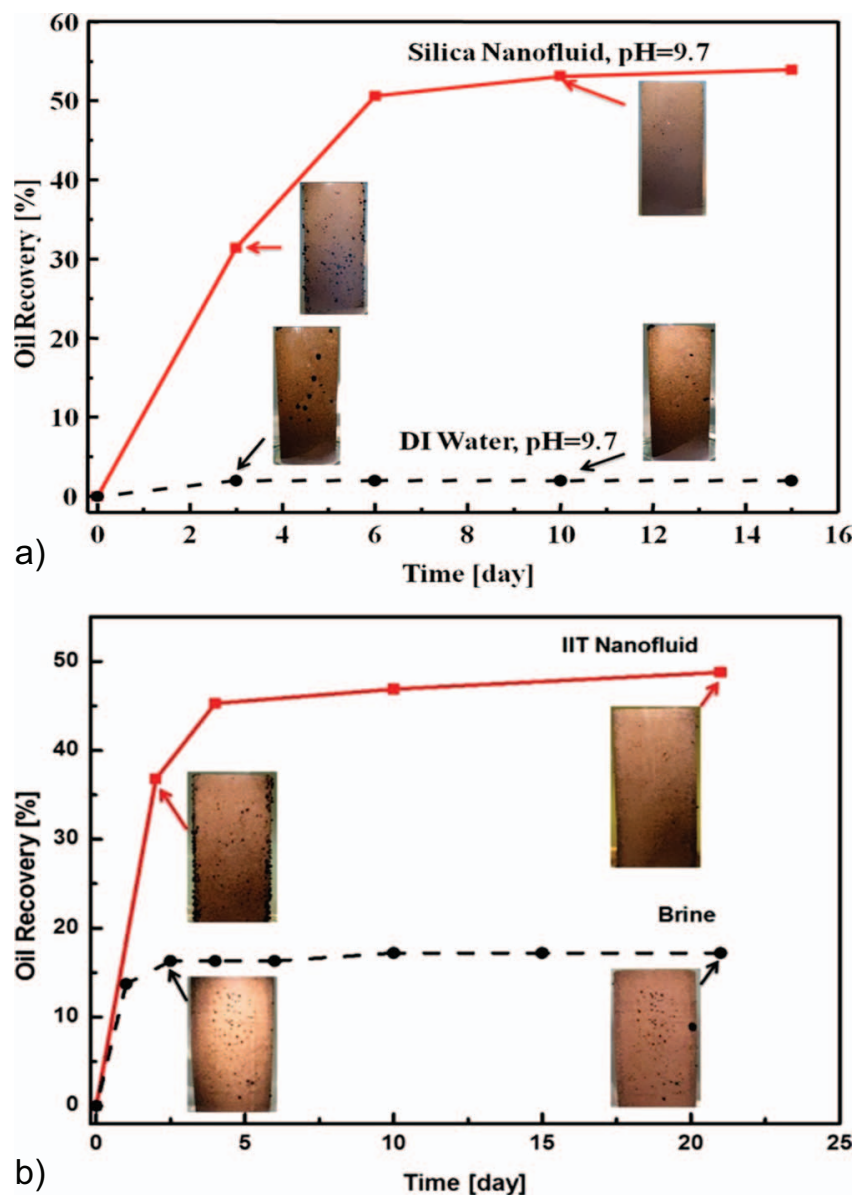

Fig. 17. Imbibition of DeIonized (DI) water, the nanofluid, and brine solution into Berea sandstone presaturated with crude oil at 25 and $55^{\circ} \mathrm{C}$ respectively (Zhang et al., 2014a). a: $25^{\circ} \mathrm{C}$; b: $55{ }^{\circ} \mathrm{C}$.

dodecyl sulfate) - polymer (SP), respectively, on wettability alteration and EOR at varying nanoparticle concentrations and temperatures. They found that the viscosity of both nanofluids with polymer (nanoparticle) and NSP was increased by a factor of about three because of the introduction of $1.0 \mathrm{wt} \%$ silica nanoparticles, compared with that of polymer and SP solutions, as shown in Figure 23. The increase in viscosity of nanofluids was greater at higher temperatures. Note that the only difference between polymer (or SP) and nanoparticle (or NSP) fluids is that $1.0 \mathrm{wt} \% \mathrm{SiO}_{2}$ nanoparticles were added in nanoparticle fluid.

The IFT data of different crude oil-fluid systems at different temperatures measured by Sharma et al. (2016) are depicted in Figure 24. The addition of the $1.0 \mathrm{wt} \%$ $\mathrm{SiO}_{2}$ nanoparticles decreased the IFT of both nanoparticle and NSP nanofluid-crude oil systems significantly, especially at low temperatures.

The pressure drops, as reported by Sharma et al. (2016), during nanoparticle and NSP nanofluid flooding were higher than those during flooding without nanoparticles, which was reasonable because the viscosity of nanoparticle and NSP fluids were increased by the addition of the
1.0 wt\% $\mathrm{SiO}_{2}$ nanoparticles. The pressure drop could relaxed back to its initial values $(0.05-0.07 \mathrm{MPa})$ at the end of the chase brine flood for polymer and SP flooding but could not for nanoparticle and NSP flooding, which indicates that the permeability of the sand pack decreased after nanoparticle/NSP nanofluid injection, due to nanoparticle adsorption/retention (Fig. 25).

The addition of the $1.0 \mathrm{wt} \% \mathrm{SiO}_{2}$ nanoparticles in both polymer and surfactant-polymer fluids could enhance the oil recovery based on the data from Sharma et al. (2016), as shown in Figure 25. It was observed that the EOR by adding $1.0 \mathrm{wt} \% \mathrm{SiO}_{2}$ nanoparticles in surfactant-polymer was greater than that in polymer flooding. The higher the temperature was, the greater the recovery enhancement.

Sharma et al. (2016) did not measure the contact angles to determine the wettability alteration directly. Instead, they tested the ability of $\mathrm{SiO}_{2}$ nanofluids to change relative permeabilities. The results (Fig. 26) demonstrated that the nanofluids shifted wettability from intermediate- to strongly water-wetness. The concentration of nanoparticles used for measuring relative permeability was $0.1 \mathrm{wt} \%$ instead of $1.0 \mathrm{wt} \%$, as used in the core flooding experiments.

One of the problems in the area of nanofluid EOR is that it is unclear if the observed effect has been due to the stabilizers (surfactants in many cases), the nanoparticles, or a combination of both. Hu et al. (2016) conducted experiments in order to distinguish the effects of rutile $\mathrm{TiO}_{2}$ nanoparticle-assisted brine flooding on EOR. They synthesized rutile ellipsoid $\mathrm{TiO}_{2}$ nanoparticles for brine flooding of water-wet Berea sandstone cores and examined the relative contributions from the stabilizer and the nanoparticles of different concentrations to the modified flooding results.

$\mathrm{Hu}$ et al. (2016) observed that adding the $0.3 \mathrm{wt} \%$ stabilizer of trisodium citrate dihydrate (SCD) reduced the viscosity of brine significantly and increased the IFT slightly, but the effective viscosity was almost unchanged after the addition of 10-500 ppm nanoparticles. This might be because of the small particle concentration. The effect of nanoparticles on IFT was not monotonic while the variation was small, having a maximum value of $49.0 \pm$ $0.8 \mathrm{mN} / \mathrm{m}$ at $50 \mathrm{ppm}$ and a minimum of $44.5 \pm 0.4 \mathrm{mN} /$ $\mathrm{m}$ at $500 \mathrm{ppm}$ (Figs. 27a and 27b). Note that the IFT at $50 \mathrm{ppm}$ of nanoparticles was greater than that (about $47.5 \mathrm{mN} / \mathrm{m}$ ) of brine/oil. Hu et al. (2016) did not explain the reason or mechanism behind this observation. The addition of nanoparticles decreases the IFT in many cases (Suleimanov et al., 2011; Zhang et al., 2014a; Moradi et al., 2015).

As shown in Figure 28, the average oil recovery by brine only flooding was about $30.3 \%$, and a similar value (i.e., $30.5 \%$ ) was found for flooding with BSF (brine with stabilizer fluid), a mixture of brine and the $0.3 \mathrm{wt} \%$ SCD stabilizer. This demonstrates that the influence of the stabilizer on the oil recovery was negligible. As pointed out by $\mathrm{Hu}$ et al. (2016), however, this is not a universal conclusion. Other stabilizers, especially some designed surfactants, could affect the oil recovery. The values of oil recovery were strongly dependent on the particle concentration with a nonmonotonic correlation (Fig. 28). 


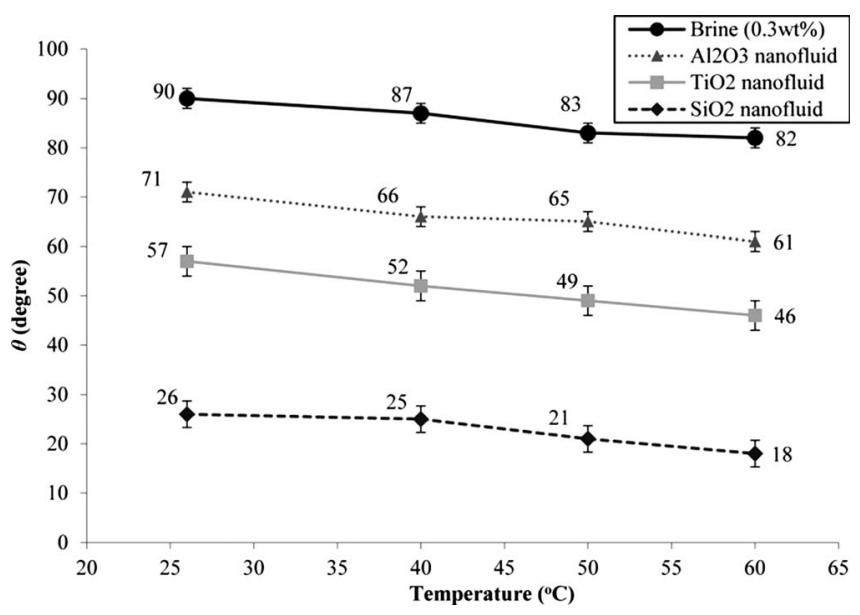

Fig. 18. Contact angle of oil/aqueous phases on the limestone surface at different temperatures and at ambient pressure (Esfandyari Bayat et al., 2014).

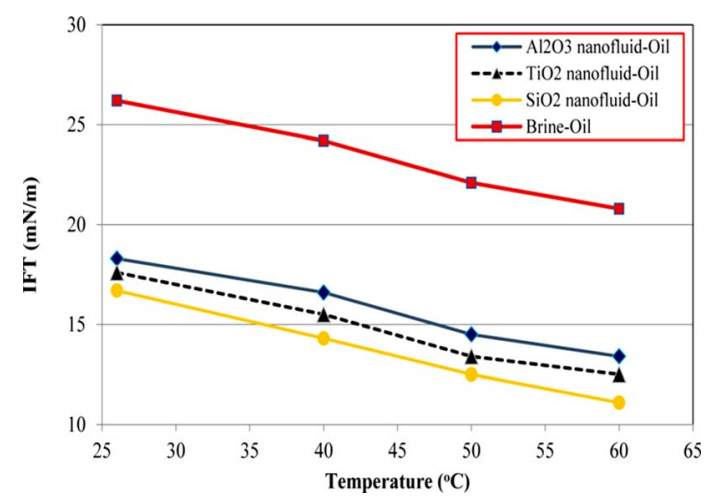

Fig. 19. IFT of oil/aqueous phases at different temperatures and at ambient pressure (Esfandyari Bayat et al., 2014).

The oil recovery at water Breakthrough point (BOR) is different from the oil recovery at residual oil saturation (Ultimate Oil Recovery, UOR) and shows different performance in many cases. For this reason, the results of oil recovery at breakthrough reported by $\mathrm{Hu}$ et al. (2016) are listed in Figure 29. One can see that adding $\mathrm{TiO}_{2}$ nanoparticles could enhance BOR significantly, but not monotonically. At lower nanoparticle concentrations, the oil recovery increases with the nanoparticle concentration, reaching the maximum value, $39.8 \%$, at about $20 \mathrm{ppm}$. This represents about $9.5 \%$ incremental increase in BOR compared to the brine flooding $(30.3 \%)$. BOR starts to decrease with the increase in nanoparticle concentration after the peak. About 35.8\% of the Oil Originally In Place (OOIP) was recovered at the lowest nanoparticle concentration tested (5 ppm), around $5.5 \%$ incremental increase in BOR compared to the brine flooding (30.3\%). The enhanced BOR is less than the enhanced UOR.

The values of UOR are also shown together with those at breakthrough in Figure 29. The general dependence of the UOR on nanoparticle concentration was similar to BOR, but the peak value of UOR occurred at a nanoparti-

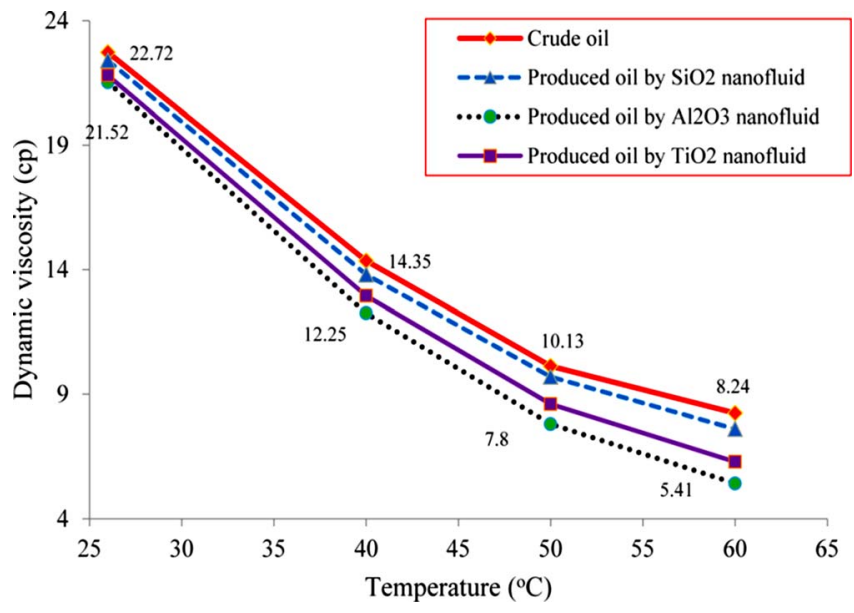

Fig. 20. Oil viscosity before and after the nanofluids flooding at different temperatures and at ambient pressure (from Esfandyari Bayat et al., 2014).

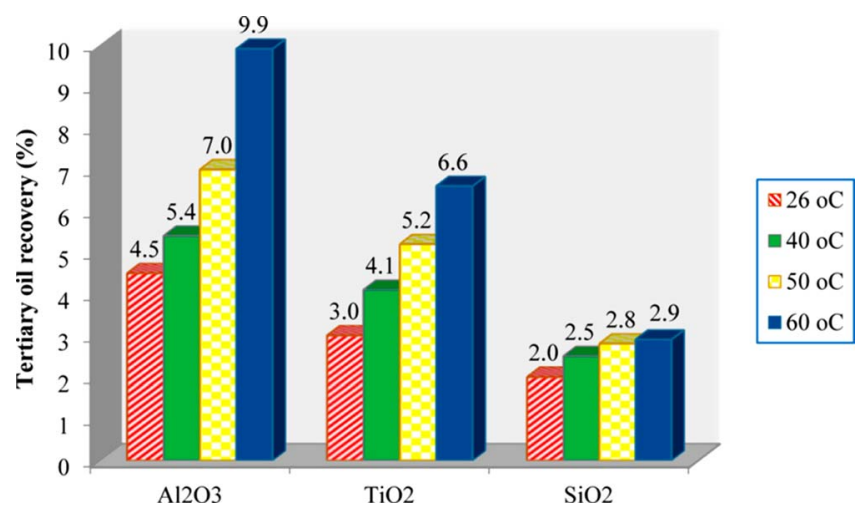

Fig. 21. Oil recovery via $\mathrm{Al}_{2} \mathrm{O}_{3}, \mathrm{TiO}_{2}$, and $\mathrm{SiO}_{2}$ nanofluids at different temperatures after brine flooding stage (from Esfandyari Bayat et al., 2014).

cle concentration of $10 \mathrm{ppm}$ instead of $20 \mathrm{ppm}$, with a total oil recovery of $41.8 \%$ of OOIP, representing an $11.5 \%$ increase in oil recovery compared to the scenario of waterflooding without adding the nanoparticles.

$\mathrm{Hu}$ et al. (2016) measured three differential pressure profiles during the different types of flooding (Fig. 30). The nanofluid flooding showed a higher pressure drop than that of brine only flooding but lower than the brine flooding with stabilizer case. This, as explained by $\mathrm{Hu}$ et al. (2016), was due to that most of the stabilizers were on the surface of nanoparticles, and the quantity of loose stabilizer in the brine was small, hence reducing the possibility of stabilizer jamming. In addition, nanoparticles also tended to mobilize or assist in migrating stabilizers stuck in the core samples and mobilize the residual oil during the flooding process.

Interestingly, Hu et al. (2016) observed that nanoparticle transport is strongly dependent on its concentration. The outlet-to-inlet concentration ratio, $\mathrm{C} / \mathrm{C}_{0}$, generally decreases with increasing nanoparticle concentration, as shown in Figure 31. They did not report, unfortunately, the values 


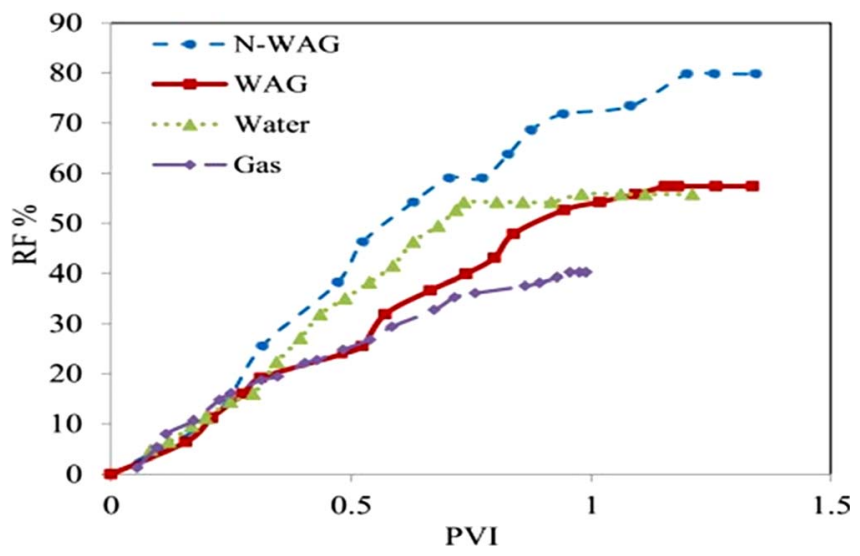

Fig. 22. Recoveries versus PV injected with and without nanoparticles (from Moradi et al., 2015).

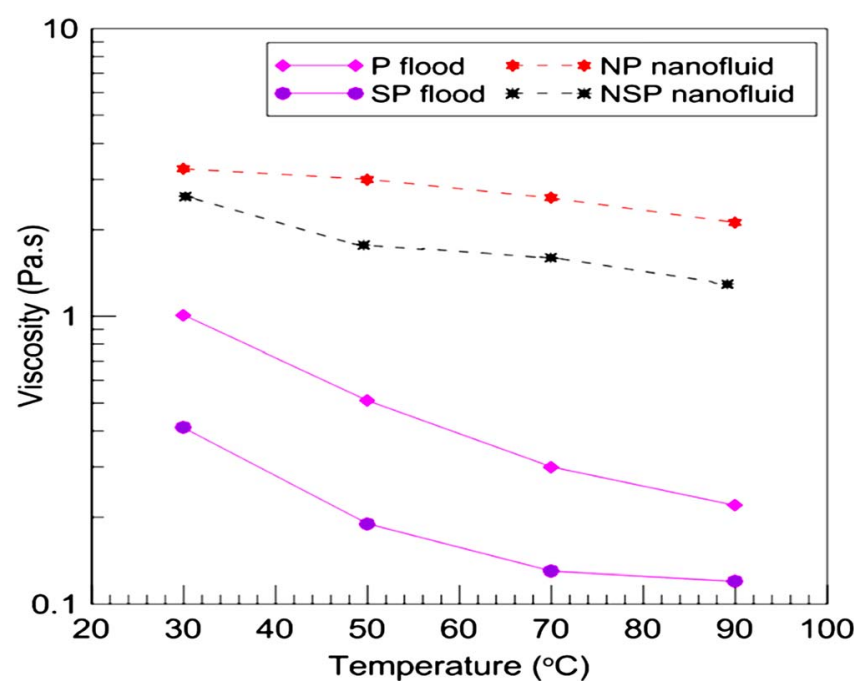

Fig. 23. Effect of temperature on the viscosity of various fluids/nanofluids (nanoparticle and NSP nanofluids with $1.0 \mathrm{wt} \% \mathrm{SiO}_{2}$ nanoparticles) at different temperatures (from Sharma et al., 2016).

of $\mathrm{C} / \mathrm{C}_{0}$ at the concentration of $20 \mathrm{ppm}$ at which the EOR reached the maximum value (Fig. 29). It is not clear whether the values of $\mathrm{C} / \mathrm{C}_{0}$ at $20 \mathrm{ppm}$ is greater or smaller than those of $10 \mathrm{ppm}$, which may be helpful to explain why EOR had a peak at $20 \mathrm{ppm}$. Another phenomenon seen in Figure 31 is that the values of $\mathrm{C} / \mathrm{C}_{0}$ at $10 \mathrm{ppm}$ are greater than $100 \%$. $\mathrm{Hu}$ et al. (2016) speculated that the presence of salt tends to form aggregates, leading to a large absorbency increase and a higher than unity $\mathrm{C} / \mathrm{C}_{0}$ value. The question, however, is that the formation of aggregates could happen at other nanoparticle concentrations such as 50, 100, and $500 \mathrm{ppm}$.

$\mathrm{Hu}$ et al. (2016) reported that the viscosity of the produced oil after nanofluid flooding was reduced and the wettability was altered to more water-wetness (the contact angle decreased from about $18-8^{\circ}$ ) because of the addition of the nanoparticles.

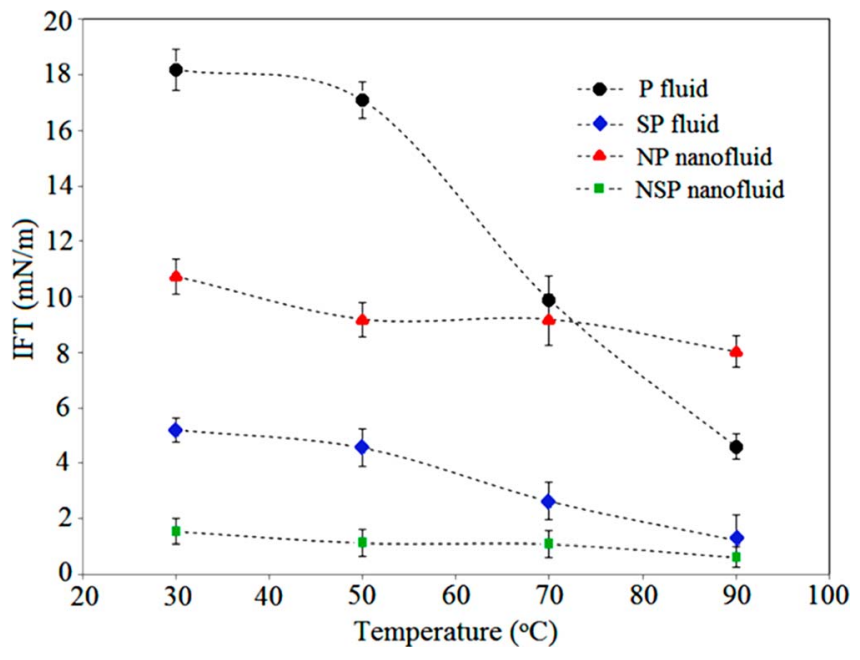

Fig. 24. IFTs measured for different crude oil-fluid systems (P, SP, nanoparticle, and NSP) as a function of temperature. The nanoparticle and NSP nanofluids had a 1.0 wt\% $\mathrm{SiO}_{2}$ concentration (from Sharma et al., 2016).

Finally, $\mathrm{Hu}$ et al. (2016) analyzed the possible mechanisms for EOR by nanoparticles and suggested that the mechanisms might be a combination of mobility ratio modification, rock wettability alteration to more water wetness, and the log-jamming effect while the exact causes are unknown yet. $\mathrm{Hu}$ et al. (2016) concluded that the SDP might not be important in terms of EOR.

\subsection{Other mechanisms}

Metin et al. (2012) investigated the adsorption of surface functionalized silica nanoparticles onto mineral surfaces at decane/water interfaces. Silica nanoparticles with four different surfaces, i.e., unmodified, modified with anionic (sulfonate), cationic (quaternary ammonium, referred to as "quat"), and nonionic (polyethylene glycol, referred to as "PEG") surfactant, were used. The size of the silica nanoparticles ranged from 5 to $75 \mathrm{~nm}$. The concentrations of nanoparticles were $0.04,0.2$, and $1 \%$ wt. They found that the unmodified silica nanoparticles at various concentrations had little effect on IFT of water/decane interface (changing from 45 to 43 dynes $/ \mathrm{cm}$ ). The surface-modified silica nanoparticles with sulfonate did not affect the IFT either. A slight decrease was observed as nanoparticle concentration increased, but this decrease might be due to the presence of the sulfonate surface modifier. When the values of IFT in presence of sulfonate-modified particles were compared with just the sulfonate modifier in water, almost the same decrease in IFT was observed. The contact angle was changed slightly by the presence of either unmodified or surface-modified nanoparticles with anionic, cationic or nonionic surfactants (sulfonate, quat, or PEG) but was not altered by the nanoparticle size. The contact angles measured by Metin et al. (2012) in the water/decane/mineral systems (i.e., the decane droplet on quartz plate immersed in water) changed over a large range from 20 to $91^{\circ}$, which 

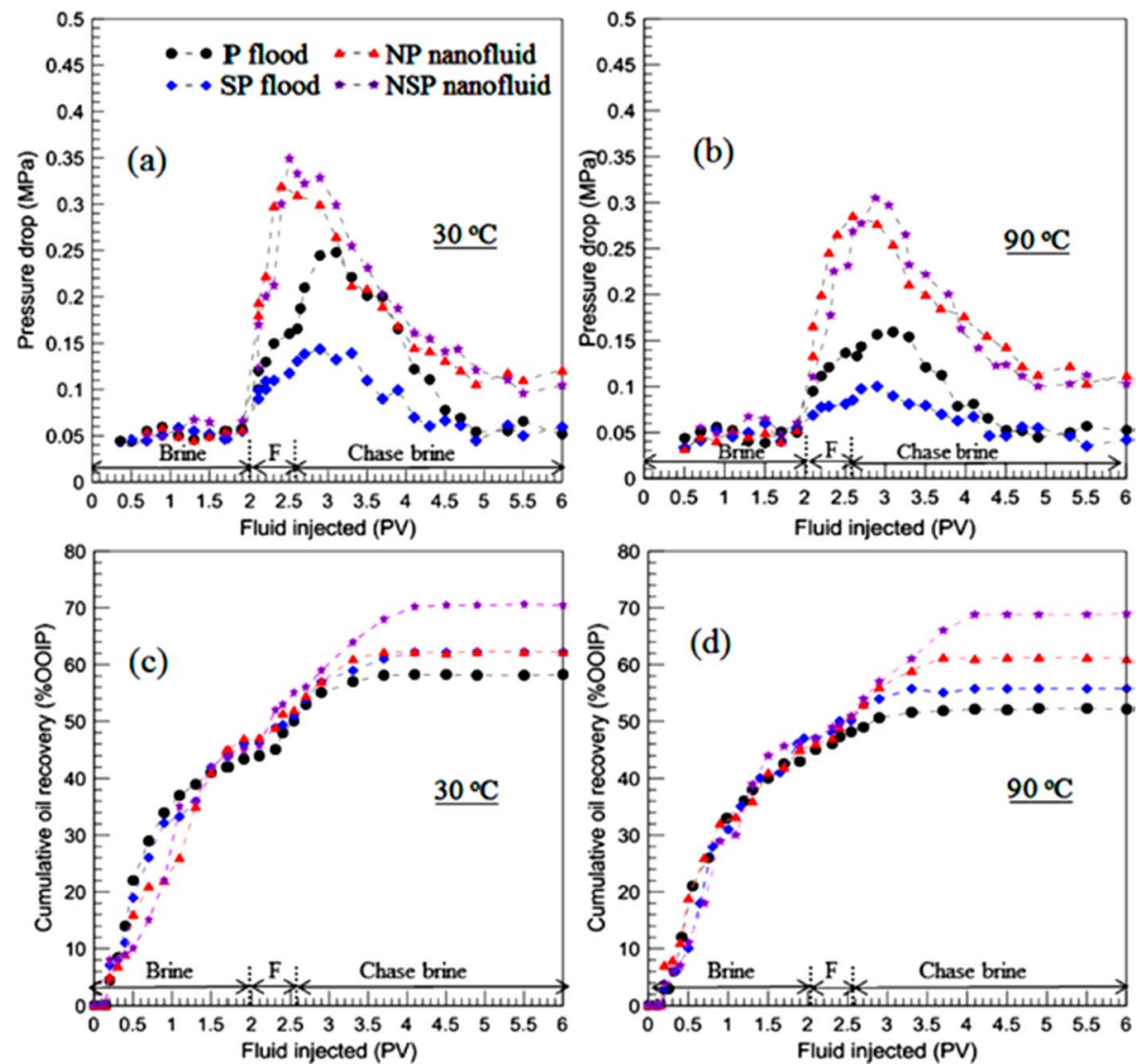

Fig. 25. Pressure drop and oil recovery as a function of fluid pore volumes injected during different flooding circumstances at 30 and $90{ }^{\circ} \mathrm{C}$ (nanoparticle and NSP nanofluids with $1.0 \mathrm{wt} \% \mathrm{SiO}_{2}$ nanoparticles), F indicates the interval when Polymer, SP, nanoparticle, and NSP nanofluids were injected (from Sharma et al., 2016).
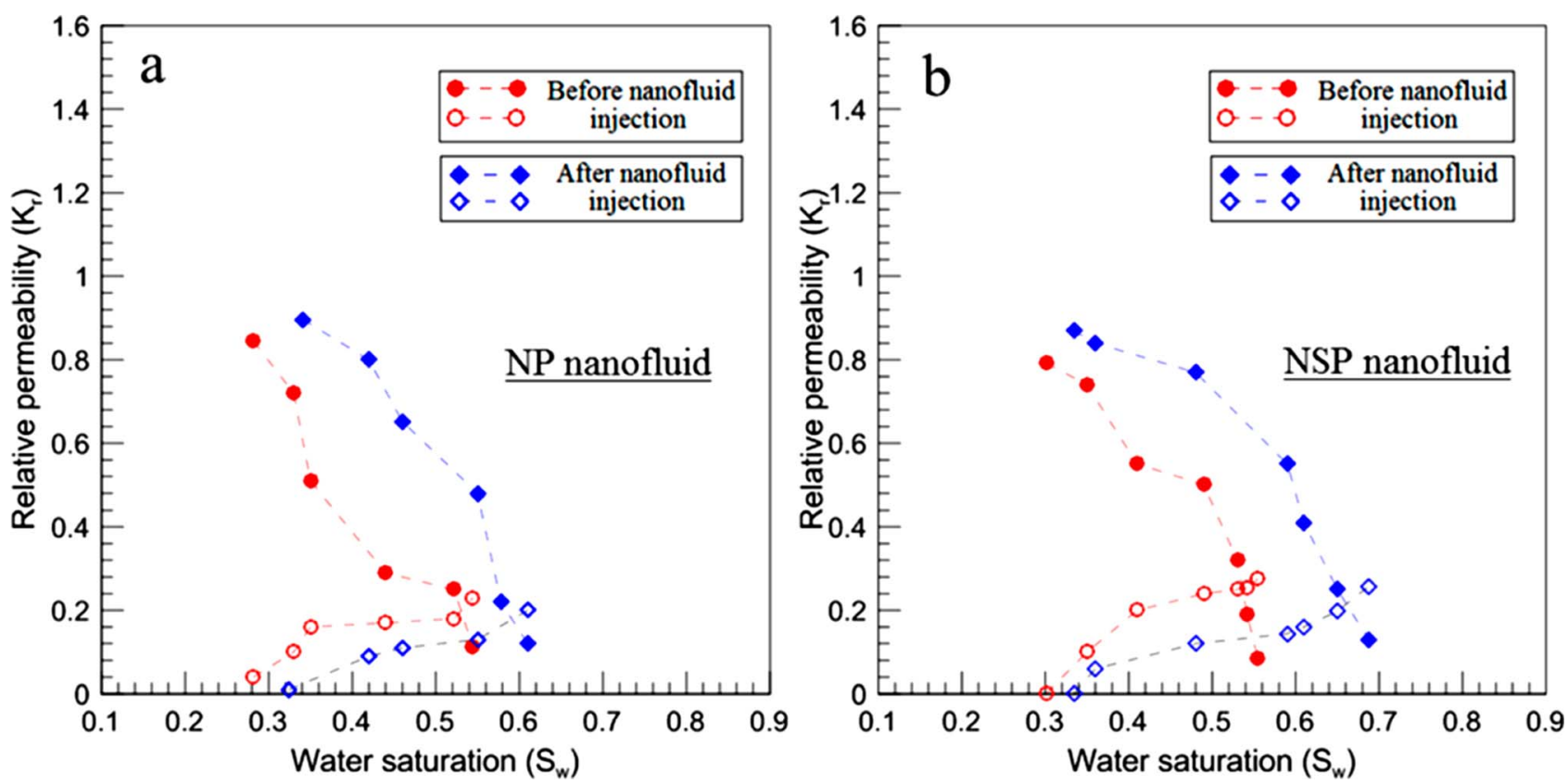

Fig. 26. Relative permeability curves for brine (empty symbols) and oil (dark symbols) before and after (a) nanoparticle and (b) NSP flood (0.1 wt\% $\mathrm{SiO}_{2}$ nanoparticles were used in the nanofluids) at $30{ }^{\circ} \mathrm{C}$ (from Sharma et al., 2016). 
(a)

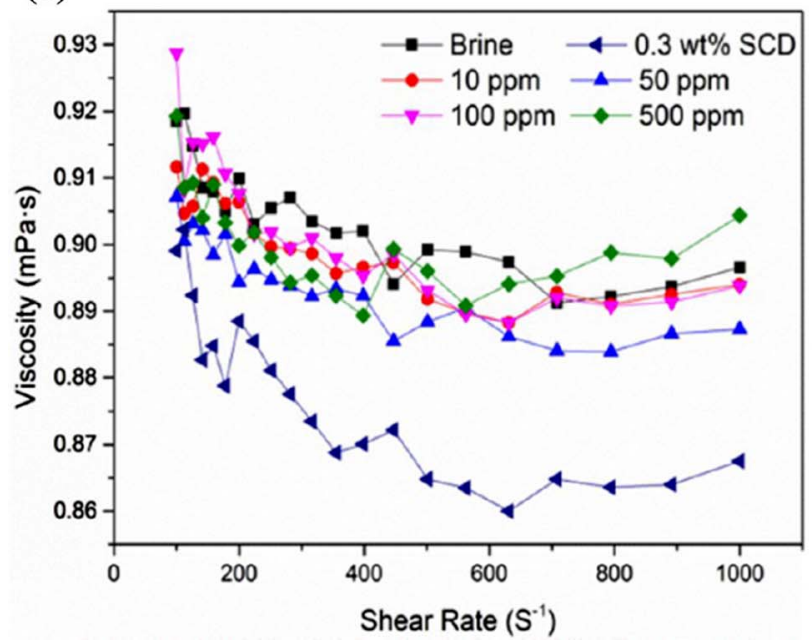

(b)

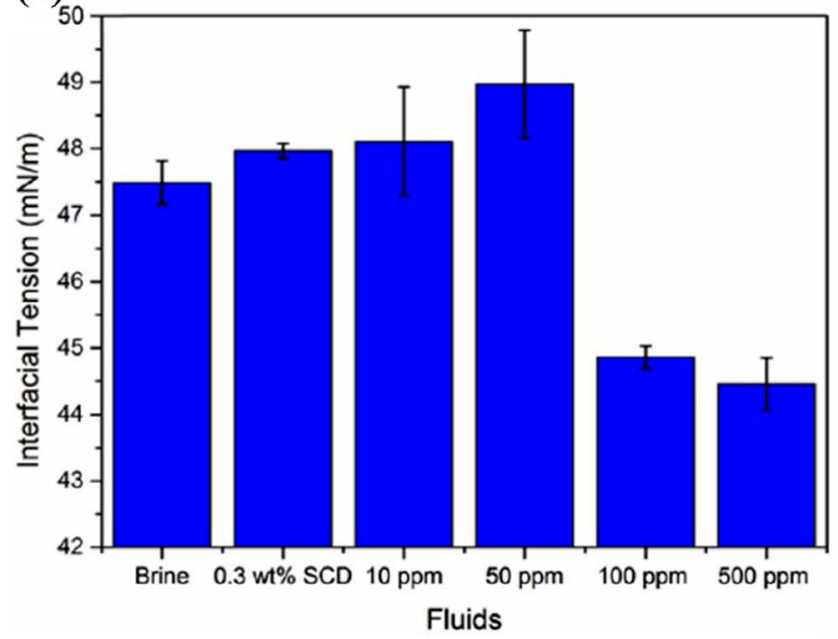

Fig. 27. a: dynamic viscosity and b: IFT of the $0.1 \mathrm{~mol} / \mathrm{dm}^{3}$ brine alone, the $0.1 \mathrm{~mol} / \mathrm{dm}^{3}$ brine with $0.3 \mathrm{wt} \%$ SCD stabilizer, and the stabilized brine with 10,50,100, and $500 \mathrm{ppm}$ of $\mathrm{TiO}_{2}$ nanoparticles (from $\mathrm{Hu}$ et al., 2016).

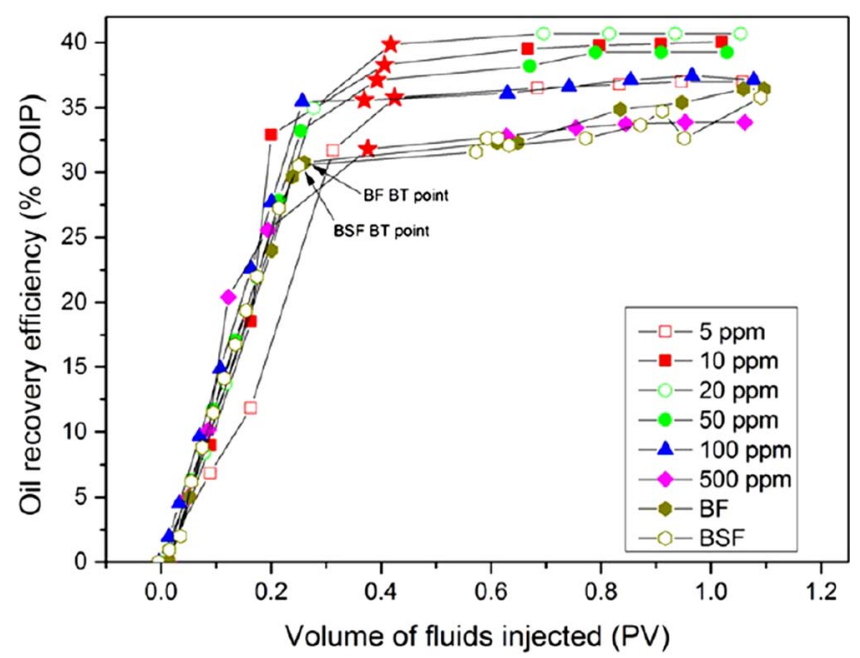

Fig. 28. Examples of the volume of oil recovered from 0 to $1 \mathrm{PV}$ expressed as a percentage of the initial oil saturation. The stabilizer is $0.3 \mathrm{wt} \% \mathrm{SCD}$, and data are given for synthetic brine $(\mathrm{BF})$, synthetic brine with stabilizer (BSF), and for synthetic brine, stabilizer, and six different concentrations of $\mathrm{TiO}_{2}$ nanoparticles. The breakthrough points are marked by red five-pointed stars (from $\mathrm{Hu}$ et al., 2016).

should not vary significantly as a reference base. They concluded that the type and amount of surface treatment attached to silica nanoparticles determine the extent of the change in IFT of water/decane interfaces. The decrease in IFT corresponds to the effect of sulfonate molecules but not to the presence of the nanoparticles. The experimental results obtained by Metin et al. (2012) are not consistent with the study of Wasan and Nikolov (2003), Binks and Whitby (2005), Lee et al. (2006) as well as Zhang et al. (2014a). Metin et al. (2012) did not measure the viscosity of nanoparticle dispersion.

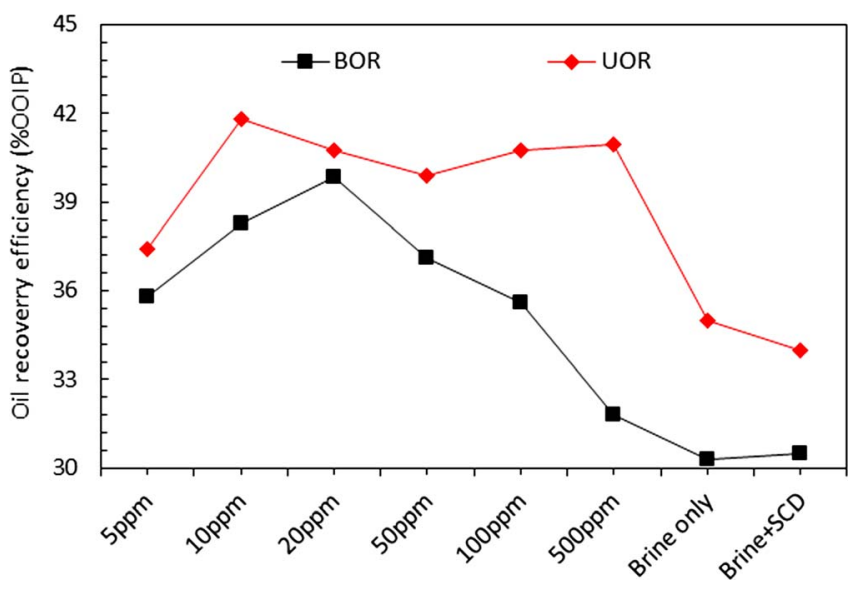

Fig. 29. Oil recovery at breakthrough expressed as a percentage of the initial oil saturation for synthetic brine (BF), synthetic brine with stabilizer (BSF), and synthetic brine + stabilizer and six different concentrations of $\mathrm{TiO}_{2}$ nanoparticles. The stabilizer is $0.3 \mathrm{wt} \% \mathrm{SCD}$ (from $\mathrm{Hu}$ et al., 2016).

Both surfactants and nanoparticles might reduce IFT, which may create some synergistic action to the formation and stabilization of oil-in-water emulsions (Somasundaran et al., 2007; Dickinson, 2012; Worthen et al., 2013, 2014). Figure 32 (Worthen et al., 2014) shows the contour maps of the emulsion stability to creaming (herein referred to as "stability maps") for dodecane-in-SSW (Synthetic SeaWater) preparations at aqueous-phase fractions $\varphi_{\mathrm{w}}=0.2$, 0.5 , and 0.8 , where the warmth of the color indicates the length of time required for $20 \%$ of the total aqueous-phase volume to resolve. Greater time reflect greater emulsion stability. As shown in Figure 32, Worthen et al. (2014) found that the combination of the nanoparticles and surfactant could produce emulsions with smaller oil droplets and greater stability to coalescence than the emulsions stabilized by 


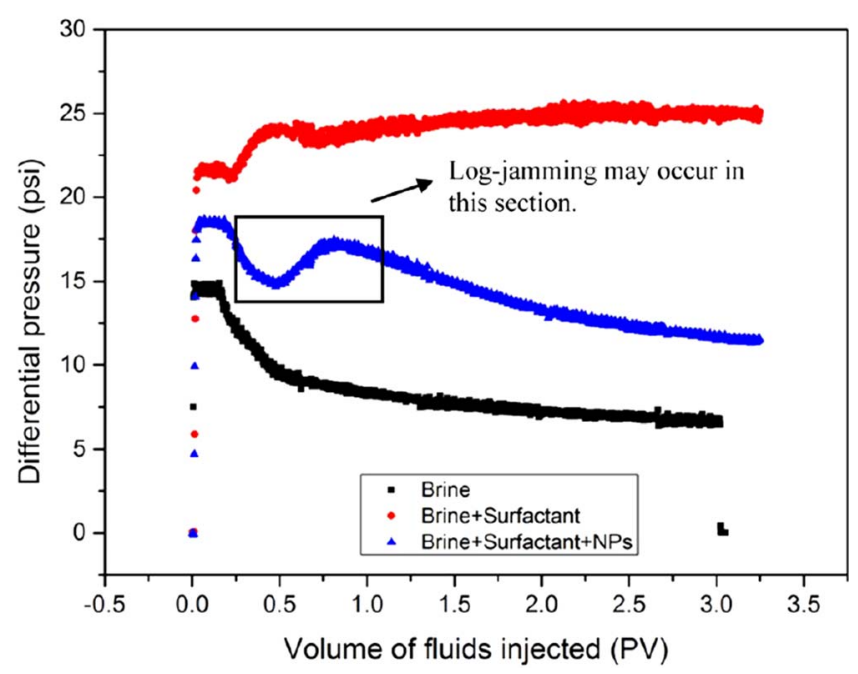

Fig. 30. Pressure profiles for brine (black points), brine with stabilizer/surfactant (red points), and a $500 \mathrm{ppm} \mathrm{TiO}_{2}$ nanofluid (blue points) flooding on core SZ4 (from Hu et al., 2016).

either nanoparticles or surfactant alone. The synergy for emulsion formation and stabilization for the two amphiphiles was even greater in the case of a high-salinity SSW aqueous phase. The possible reason for the synergistic phenomenon is the unusually greater concentrations of nanoparticles and surfactant adsorbed at the oil-water interface and lowering of the IFT because of the weak adsorption of the highly hydrophilic surfactant on the anionic nanoparticles along with the high critical micelle concentration.

The synergistic action of surfactants and nanoparticles is of interest in numerous applications, including foodstuffs (Dickinson, 2012), cosmetics (Somasundaran et al., 2007), and oil-spill remediation (Li et al., 2007). There have been a few reports on the application of the synergistic action of surfactants and nanoparticles in oil recovery. Although Worthen et al. (2013) investigated the effect of the synergy on the stabilization of the carbon dioxide-in-water foams with nanoparticles and surfactant, no oil recovery enhanced by the synergistic action has been measured.

It may be very interesting to evaluate the values of the oil recovery enhanced by the synergistic action of surfactants and nanoparticles at different situations.

\section{Discussion and analysis on the mechanisms of nanofluid EOR}

One can see from Table 1 that most of the researchers proposed more than one mechanisms for nanofluid EOR. Those proposals have been made based on the experimental data and observations. Therefore, it may be the most acceptable idea that nanofluid EOR could be a combination of different mechanisms. The question is which mechanisms are the major or dominated ones. Another question is which mechanisms are independent or dependent with each other. According to the results listed in Table 1 and the above analysis conducted in this paper, wettability alteration

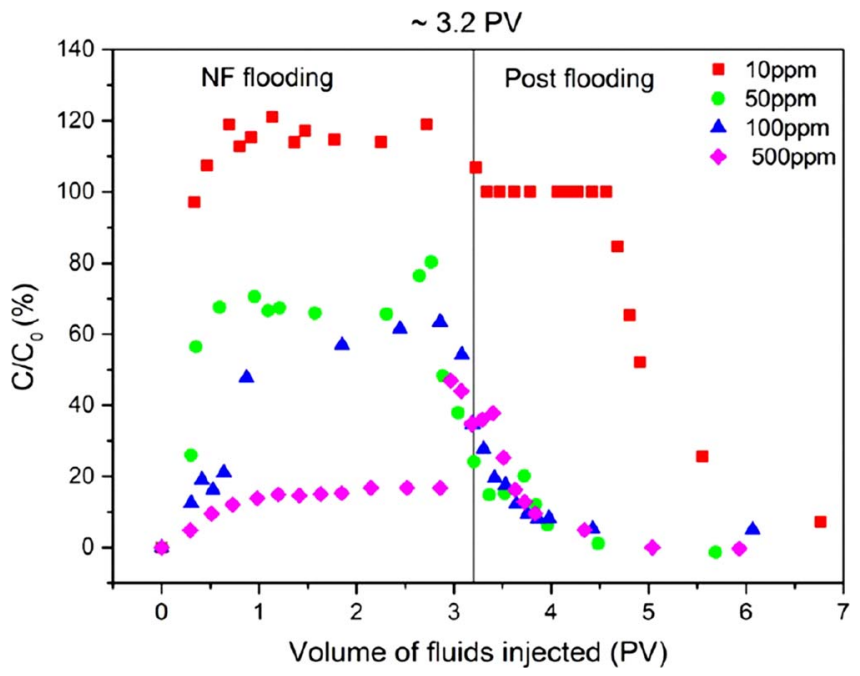

Fig. 31. Particle breakthrough ability during flooding with four different concentrations of $\mathrm{TiO}_{2}$ nanofluid and subsequent post flooding with synthetic brine. $\mathrm{C}_{0}$ is the concentration of initial fluids before NF flooding (from $\mathrm{Hu}$ et al., 2016).

may be the most agreed-upon and the most important mechanism of nanofluid EOR. The question about dependency of different mechanisms is discussed and analyzed in the following section.

Many experiments have been conducted to investigate the mechanisms of EOR by using nanoparticles. A few mechanisms of nanofluid EOR have been proposed according to the experimental data or the modeling results, as analyzed in the preceding sections. Because of the inconsistency among the experimental data and results reported by different researchers, the mechanisms proposed to explain nanofluid EOR have been neither the same nor all accepted. For example, Metin et al. (2012) reported that unmodified silica nanoparticles at various concentrations $(0.04,0.2$, and $1 \% \mathrm{wt}$ ) had little effect on IFT of water/decane interface (changing from 45 to 43 dynes $/ \mathrm{cm}$ ) and wettability. El-Diasty and Aly (2015) concluded that the mechanisms for nanofluid EOR are SDP, wettability alteration and log-jamming. Hu et al. (2016) suggested that the mechanisms for nanofluid EOR might be a combination of mobility ratio modification, rock wettability alteration to more water wetness, and the log-jamming effect but the SDP may not be important in terms of EOR. Wettability alteration to more water-wetness, according to our summary (Table 1), seems to be one of the mostly accepted mechanisms for nanofluid EOR. Only one study (Metin et al., 2012), among all of the reviewed publications, reported no wettability alteration by nanofluid. One of the big issues in the data reported by Metin et al. (2012) is that the measured contact angles had a great scattering range from 20 to $91^{\circ}$. Therefore, it is almost sure that wettability alteration is one of the mechanisms for EOR by nanofluids. However, what causes wettability alteration, SDP, is not all agreed. As discussed previously, SDP requires high nanoparticle volume fraction (greater than 20\%), which is not the actual case where very low nanoparticle concentration $(0.01 \%)$ is used (Chengara et al. 2004; Wen, 2008). 


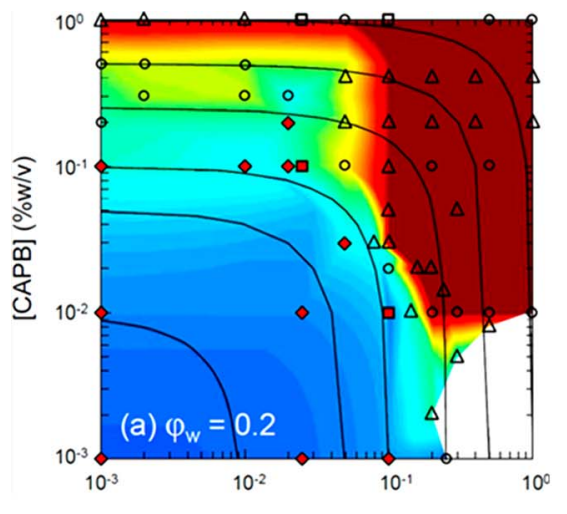

[NP] $(\% w / v)$
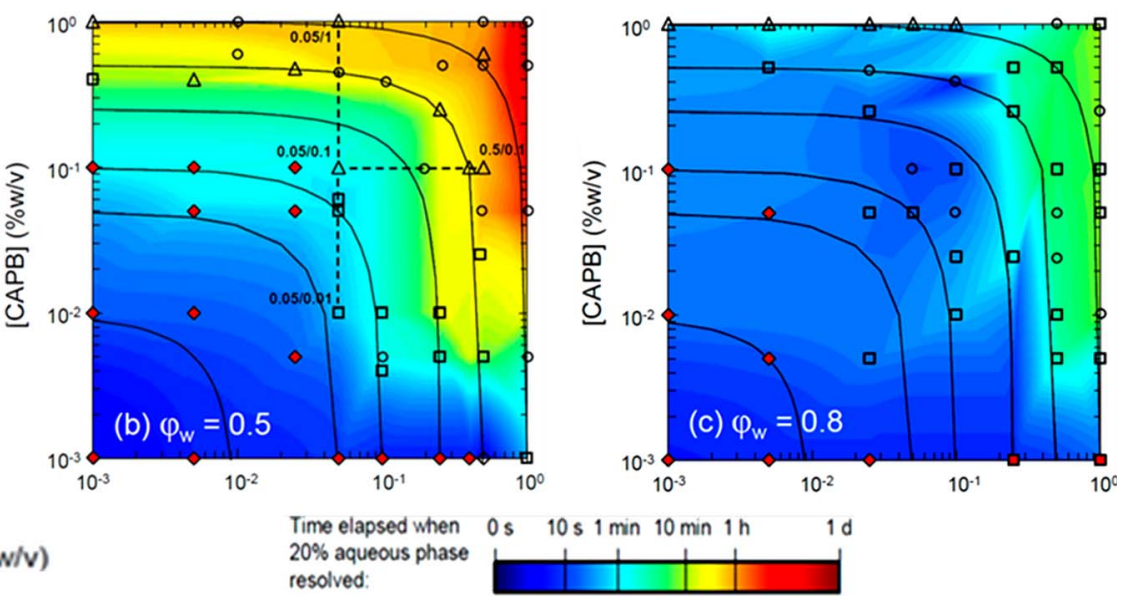

Fig. 32. Creaming stability for dodecane-in-SSW emulsions at a water fraction $\left(\varphi_{\mathrm{w}}\right)$ of (a) 0.2 , (b) 0.5 , and (c) 0.8 as plotted in contour maps as a function of the nanoparticle concentration and CAPB concentration with respect to time (from Worthen et al., 2014).

Reduction in IFT is another mechanism of nanofluid EOR, proposed by many but few have reported the experimentally measured data of IFT before and after the addition of nanoparticles (Table 1). Stabilizers or other surfactantlike chemicals have been added in the nanofluids in most of the publications that reported reduction in IFT. Note that IFT will definitely be reduced if nanoparticles are doped with surfactant groups and surface modified. As pointed out by Lim et al. (2015), a study using a pure nanofluid system (just nanoparticles, without any surface-active impurities) needs to be conducted in order to establish conclusively the role of the nanoparticles in altering IFT and surface wettability. $\mathrm{Hu}$ et al. (2016) conducted such a study and found little effect of nanoparticle addition on IFT. Esfandyari Bayat et al. (2014), however, reported significant reduction in IFT by the addition of nanoparticles in pure water or brine.

One can see from this discussion and the IFT data shown in Table 1 that it is difficult to conclude the effect of nanoparticle on IFT. The synergistic effects of surfactants and nanoparticles on IFT, however, might be acceptable in many cases. The point is, the addition of nanoparticles could enhance the ability of surfactants to reduce IFT even though nanoparticles only could not reduce IFT.

In the point of view of fluid flow mechanics, logjamming theory is very possible to be one of the mechanisms for nanofluid EOR. Log-jamming is a double-edge sword though; it may increase oil recovery but may also decrease it because the nanoparticle blocking may reduce the permeability significantly. Nonetheless, the size of nanoparticles may be important. The permeability reduction phenomenon may be dominant if the nanoparticle size and/or the concentration are big and high enough. The jamming effect may not be sufficient if the nanoparticle size or the concentration is too small and then the increase in oil recovery is not significant. According to this, an optimized nanoparticle size or concentration may exist, which has been found to be true by El-Diasty and Aly (2015) and others (Hendraningrat and Torsaeter, 2014). This observation, to some extent, also implies that log-jamming may be one of the mechanisms for nanofluid EOR.
It is almost sure that the addition of pure nanoparticles into water will increase the viscosity of the aqueous solution, which will improve the sweep efficiency and eventually increase the oil recovery. The only concern is how much oil recovery could be enhanced because low or very low concentration of nanoparticles are usually utilized and the increase in viscosity may be limited. Ehtesabi et al. (2014) found that $\mathrm{TiO}_{2}$ nanoparticles do not change the viscosity and the IFT significantly.

Ogolo et al. (2012) reported a decrease in oil viscosity by the addition of aluminium oxide nanoparticles. However, they did not provide the corresponding experimental data. Esfandyari Bayat et al. (2014) provided the experimental data of the viscosity of the produced crude oil but the reduction in oil viscosity is not very noteworthy at low temperatures. Decrease in oil viscosity, as one of the mechanisms for nanofluid EOR, may need further systematic study. Note that it is possible to reduce the oil viscosity by adding nanoparticles in crude oil but it requires high temperature or other conditions. As reported by Li et al. (2014), the viscosity of heavy crude oil could be reduced over $96 \%$ and the heavy oil could be efficiently upgraded to light oil at a relatively low temperature of about $150{ }^{\circ} \mathrm{C}$ by adding carbon nanoparticles in crude oil. The temperature of crude oil was increased by microwave heating.

For the climbing film and slug-like displacement mechanism proposed by Luo et al. (2016), the situation is complex because the nanoparticles used in this case were graphenebased amphiphilic Janus nanosheets. One of their features is that the surface of the nanoparticles or nanosheets has been modified to have both hydrophilic and hydrophobic faces (Luo et al., 2017). Another feature is that the shape is not spherical as was that of nanoparticles used in most cases for EOR. As pointed out by Xiang et al. (2017), one of the intriguing properties of Janus nanoparticles is their superior affinity toward interfaces and they can serve as solid surfactants. Further considering the possible contact angle change or wettability alteration in Figure 15, the climbing film and slug-like displacement phenomenon proposed by Luo et al. (2016) might be associated with both 
reduction in IFT and alteration in wettability for EOR by adding the graphene-based amphiphilic Janus nanosheets.

The log-jamming effect, increase in the viscosity of the water phase as the flooding fluid, and the decrease in oil viscosity (if this is verified) may be independent mechanism of nanofluid EOR. As mentioned previously, wettability alteration may be one of the most agreed-upon mechanisms for EOR by nanofluids. However, wettability alteration may not be an independent mechanism. This is because wettability or contact angle is dependent upon disjoining pressure. The film-meniscus microscopic contact angle, $\theta_{\mathrm{e}}$, is given by the Frumkin-Derjaguin equation (Frumkin, 1938):

$$
\prod_{0}\left(h_{e}\right) h_{e}+\int_{h_{e}}^{\infty} \prod(h) \mathrm{d} h=\sigma_{\frac{0}{l}}\left(\cos \theta_{e}-1\right)=S,
$$

where $S$ is the spreading coefficient and $\sigma$ is the IFT between oil (o) and the nanofluid $(\ell), h_{e}$ is the equilibrium thickness of a thin film, $\Pi_{0}$ is represented by the sum of the capillary pressure $P_{\mathrm{c}}$ and the hydrostatic pressure of the droplet $P_{\mathrm{g}}$, and $\Pi$ is the disjoining pressure represented by three major terms:

$$
\Pi=\Pi_{\mathrm{vw}}+\Pi_{\mathrm{d}}+\Pi_{\mathrm{st}},
$$

where $\Pi_{\mathrm{vw}}$ represents the short-range van der Waals force, $\Pi_{d}$ accounts for forces which are electrostatic or steric in nature and $\Pi_{\text {st }}$ represents the long range structural forces arising from the ordering of the nanofluid's particles in the wedge film.

The second term on the left side of equation 5 is the integral of the disjoining pressure over the thickness of the wedge and is defined as the film tension, i.e., the film interaction energy per unit area of the film.

One can see from the above discussion and analysis that one of the original driving forces for wettability alteration caused by the addition of nanoparticles in nanofluids may be the change in disjoining pressure.

According to the above discussion and analysis, the experimental data and results reported by different researchers are not all consistent and some are even in conflict. A reason to cause the conflict might be the utilization of surfactant or surfactant-like chemicals in the nanofluids along with the nanoparticles. These surfactants may change the rock wettability and IFT. Another related reason might be lack of control experiments in which the effect of nanoparticles on oil recovery is not singled out. On the other hand, almost all of the mechanisms of nanofluid EOR are not fully understood yet and should be investigated systematically with more controlled experiments. One of the possible and useful technologies to be used for the more controlled purpose may be the "Labs on a Chip" methodology proposed by Ayela et al. (2017).

\section{Advantages of nanofluid EOR technology}

There are many types of methods and technologies to EOR. These include alkaline flooding, surfactant flooding, polymer flooding, ASP (combined Alkaline, Surfactant, and Polymer) flooding, etc. Compared with these EOR tech- nologies, what advantages does the nanofluid EOR technology have? To answer this question, most of the advantages of nanofluid EOR technology are summarized as follows.

\subsection{Great possibility and many options to manipulate the surface property of nanoparticles}

Nanoparticles made of the same material could have different surface properties such as being hydrophilic, hydrophobic, or amphiphilic. The surface charge of nanoparticles could also be manipulated to be either negative or positive. It is difficult to realize all of these features for surfactants or polymers. However, this could be done for nanoparticles. For example, Luo et al. (2016) produced the graphene oxide nanosheets with an amphiphilic surface property by tuning the Janus balance of the graphene oxide with alkylamine.

A polymer coating on the nanoparticle surface may make the nanoparticles stay at the aqueous/oil phase interface with a desired contact angle, which helps to reduce their retention in reservoir rock.

On the other hand, the nanoparticles can be solid, magnetic, magnetostrictive, or piezoelectric, raising the possibility of external collection and control for emulsion quality, texture and destabilization.

\subsection{High surface to volume ratio}

Nanoparticles have high surface to volume ratio because of the very small diameter or size. This property may be helpful to enhance the functions of nanoparticles by increasing their specific contact area with associated fluids such as oil and water.

\subsection{Suitability in harsh environments}

It is difficult for surfactants or polymers to survive at high temperature and high salinity. For example, the surfactant SDS (sodium lauryl sulfate) will cause serious precipitation in brine with high salinity. With the extremely small size of the spherical nanoparticles, a compact and well-structured monolayer can be formed at the aqueous/nonaqueous phase interface, which renders and keep the emulsion very stable, even under severe reservoir conditions such as high temperature (Qiu and Mamora, 2010).

\subsection{Possibility to have less or no adsorption of nanoparticles on the rock surface}

One of the serious problems for chemical (surfactant, polymer, and others) flooding is the adsorption of chemicals on the rock surfaces, which will consume more chemicals and increase the cost of EOR. The adsorption of nanoparticles can be reduced or avoided by changing the surface charge property.

\subsection{Environmental safety}

The environmental concerns are serious when chemical methods such as surfactant or polymer flooding are used for EOR. Simple nanofluid (containing only nanoparticles) flooding at low concentrations ( $0.01 \mathrm{wt} \%$ or less) may be a 
promising alternative and may be safer than routine chemical flooding in terms of environmental issues. Many of the current nanoparticles are made of silica, graphene or metals. These materials are relatively less harmless than surfactants or polymers used for EOR. Note that silica is one of the main components of sandstone in which oil and gas reside in many circumstances.

\subsection{Good compatibility with other base liquids and in-situ fluids in oil reservoirs}

Many types of nanoparticles utilized for EOR are made of materials, for example, silica (Nazari Moghaddam et al., 2015) or graphene (Luo et al., 2016). These materials usually do not react chemically or physically with the in-situ fluids (oil, formation water, etc.) in oil reservoirs. This demonstrates that nanofluids for EOR may have good compatibility with in-situ fluids.

The nanoparticles can be catalytic, reactive, or associative with water-soluble polymer, surfactant molecules, or other types of chemicals to optimize the functions of the nanofluids.

\subsection{Metallic nanoparticles can be separated from oil (or water) and collected with magnetic techniques}

It is usually very difficult to separate surfactants or polymers from water in traditional EOR processes. This problem may be solved if metallic nanoparticles are used because they can be separated from oil (or water) and collected by using a magnetic technique.

\section{Disadvantages of nanofluid EOR technology}

Nanofluid EOR technology also has some disadvantages, which are summarized as follows:

- Cost for manufacturing nanoparticles is still high in many cases. Similar to other nanotechnology, the cost for manufacturing nanoparticles for EOR is also high. However, the cost may be reduced significantly with time and increase in application scale.

- Mechanisms for EOR are not fully understood. As discussed earlier, nanofluid EOR technology is relatively new and the mechanisms behind the nanofluid-EOR are not very clear or fully understood. Some of the experimental data and results from different researchers are not consistent or even conflict with each other.

\section{Conclusion}

According to the analysis and discussion to some of the important recent publications in the area of nanofluid EOR, we may obtain the following conclusions:

- The mechanisms of EOR by the addition of nanoparticles into water (without surfactants) are complex and might be a combination of rock wettability alteration from oil- to more water-wetness, the log-jamming effect, increase in the viscosity of the water phase as the flooding fluid, etc. Wettability alteration may be the most agreed-upon and the most important mechanism of nanofluid EOR.

- The SDP may be the force behind the change in wettability and other properties but has not been fully understood, considering the conflicting observations between modeling (require nanoparticle concentration greater than $15 \%$ for significant SDP change) and experimental data (oil recovery is usually enhanced at very low, usually less than 1.0\%, nanoparticle concentration). - Some proposed the reduction in IFT as one of the mechanisms of nanofluid EOR, but few have reported the IFT data measured experimentally before and after the addition of nanoparticles. Stabilizers or other surfactant-like chemicals have been added in the nanofluids in most of the publications that reported reduction in IFT. Reduction in IFT is much less possible to be one of the mechanisms of nanofluid EOR than wettability alteration in the cases where only nanoparticles are added (without surfactant or surfactant-like chemicals).

- The magnitude of EOR by nanoparticles only might be limited. The synergistic effects of surfactants and nanoparticles on IFT might be acceptable in many cases. The addition of nanoparticles could enhance the ability of surfactants to reduce IFT even though nanoparticles alone could not reduce IFT.

- The shape, size, material, and concentration of nanoparticles may determine the effect of nanofluid on EOR. The studies on the effect of nanoparticle shape have been few. Different shapes of amphiphilic Janus nanoparticles with both hydrophilic and hydrophobic faces may have a great potential to reach high EOR values. The magnitude of EOR is not inversely proportional to the nanoparticle size. An optimized nanoparticle size may exist in many cases. The effect of material type is complex. The metal nanoparticle may serve as a catalyst to decrease the viscosity of the oil phase at relatively high temperatures. It may be helpful to use metal nanoparticles in cases where the viscosity of oil is great and the temperature is high. It is almost sure that there is an optimal nanoparticle concentration for the maximum EOR to be reached.

- Log-jamming is possibly one of the mechanisms for nanofluid EOR. However, log-jamming may also decrease oil recovery because the nanoparticle blocking may reduce the permeability significantly. Nonetheless the size of nanoparticles may be important. The permeability reduction phenomenon may be dominant if the nanoparticle size and/or the concentration are big and high enough. The jamming effect may not be sufficient if the nanoparticle size or the concentration is too small and then the increase in oil recovery is not significant. According to this, an optimized nanoparticle size or concentration may exist.

- The experimental data and results reported by different researchers are not all consistent and some are even in conflict. A reason to cause the conflict might be the 
utilization of surfactant or surfactant-like chemicals in the nanofluids along with the nanoparticles. These surfactants may change the rock wettability and IFT. Another related reason might be lack of control experiments in which the effect of nanoparticles on oil recovery is singled out.

- Some of the modeling results are not consistent with experimental observation. As an example, the modeling results of SDP show that the wettability alteration requires more than $15 \%$ nanoparticle concentration. However, most of the experiments showed the enhancement of oil recovery at nanoparticle concentrations below $1.0 \%$.

- Almost all of the mechanisms of nanofluid EOR are not fully understood yet and should be investigated systematically with more controlled experiments. Nonetheless, EOR by nanofluid may have a great future.

\section{References}

Alaskar M.N., Ames M.F., Connor S.T., Liu C., Cui Y., Li K., Horne R.N. (2012) Nanoparticle and microparticle flow in porous and fractured media - an experimental study, SPEJ, https://doi.org/10.2118/146752-PA.

Alaskar M.N. (2013) In-situ multifunctional nanosensors for fractured reservoir characterization, $P h D$ Thesis, Stanford University, California.

Ayatollahi S., Zerafat M.M. (2012) Nanotechnology-assisted EOR techniques: New solutions to old challenges, in SPE International Oilfield Nanotechnology Conference and Exhibition, Society of Petroleum Engineers, SPE-157094-MS.

Ayela F., Cherief W., Colombet D., Ledoux G., Martini M., Mossaz S., Podbevsek D., Qiu X.Y., Tillement O. (2017) Hydrodynamic cavitation through "labs on a chip": from fundamentals to applications, Oil Gas Sci. Technol. - Rev. IFP Energies nouvelles 72, 4, 19.

Bennetzen M.V., Mogensen K. (2014) Novel applications of nanoparticles for future enhanced oil recovery, in International Petroleum Technology Conference, IPTC, 17857.

Binks B.P., Whitby C.P. (2005) Nanoparticle silica-stabilised oilin-water emulsions: improving emulsion stability, Colloids Surf. A 253, 1-3, 105-115.

Bolandtaba S.F., Skauge A., Mackay E. (2009) Pore scale modelling of linked polymer solution (LPS) - A new EOR process, in Paper presented at the 15th European Symposium on Improved Recovery, Paris, France.

Chengara A., Nikolov A.D., Wasan D.T., Trokhymchuk A., Henderson D. (2004) Spreading of nanofluids driven by the structural disjoining pressure gradient, J. Colloid Interface Sci. 280, 1, 192-201.

Cheraghian G., Hendraningrat L. (2016a) A review on applications of nanotechnology in the enhanced oil recovery part A: effects of nanoparticles on interfacial tension, Int. Nano Lett. 6, 2, 129-138.

Cheraghian G., Hendraningrat L. (2016b) A review on applications of nanotechnology in the enhanced oil recovery part B: effects of nanoparticles on flooding, Int. Nano Lett. 6, 1, 1-10.

De Gennes P.G. (1985) Wetting: statics and dynamics, Rev. Mod. Phys. 57, 3, 827.

Dickinson E. (2012) Use of nanoparticles and microparticles in the formation and stabilization of food emulsions, Trends Food Sci. Technol. 24, 1, 4-12.
Ehtesabi H., Ahadian M.M., Taghikhani V. (2014) Enhanced heavy oil recovery using $\mathrm{TiO}_{2}$ nanoparticles: investigation of deposition during transport in core plug, Energy Fuels 29, $1,1-8$.

El-Diasty A.I., Aly A.M. (2015) Understanding the mechanism of nanoparticles applications in enhanced oil recovery, in SPE North Africa Technical Conference and Exhibition, Cairo, Egypt, 14-16 September 2015, Society of Petroleum Engineers, Richardson, TX. SPE-175806-MS.

Esfandyari Bayat A., Junin R., Samsuri A., Piroozian A., Hokmabadi M. (2014) Impact of metal oxide nanoparticles on enhanced oil recovery from limestone media at several temperatures, Energy Fuels 28, 10, 6255-6266.

Friedheim J.E., Young S., De Stefano G., Lee J., Guo Q. (2012) Nanotechnology for Oilfield Applications - Hype or Reality? Society of Petroleum Engineers, https://doi.org/10.2118/ 157032-MS.

Frumkin A. (1938) On phenomena of wetting and adhesion of bubbles. I. Zhurnal Fizicheskoi Khimii, J. Phys. Chem. 12, 337-345, in Russian.

Haroun M.R., Alhassan S., Ansari A.A., Al Kindy N.A.M., Abou Sayed N., Abdul Kareem B.A., Sarma H.K. (2012) Smart nano-EOR process for Abu Dhabi carbonate reservoirs, Society of Petroleum Engineers, https://doi.org/10.2118/ 162386-MS.

Hendraningrat L., Shidong L., Torsaeter O. (2012) A glass micromodel experimental study of hydrophilic nanoparticles retention for EOR project, in SPE Russian Oil and Gas Exploration and Production Technical Conference and Exhibition, Moscow, Russia, 16-18 October 2012, Society of Petroleum Engineers: Richardson, TX, SPE-159161-MS.

Hendraningrat L., Li S., Torsæter O. (2013) A coreflood investigation of nanofluid enhanced oil recovery, J. Petrol. Sci. Eng. 111, 128-138.

Hendraningrat L., Torsaeter O. (2014) Unlocking the potential of metal oxides nanoparticles to enhance the oil recovery, in Offshore Technology Conference-Asia. OTC-24696.

Hirasaki G.J. (1991) Wettability: fundamentals and surface forces, SPE Form. Eval. 6, 02, 217-226.

$\mathrm{Hu}$ Z., Siddeequah M.A., Ghulam R., Paul W.J.G., Dongsheng W. (2016) Nanoparticle-assisted water-flooding in Berea sandstones, Energy Fuels 30, 4, 2791-2804.

Idogun A.K., Iyagba E.T., Ukwotije-Ikwut R.P., Aseminaso A. (2016) A review study of oil displacement mechanisms and challenges of nanoparticle enhanced oil recovery, in Nigeria Annual International Conference and Exhibition, Society of Petroleum Engineers, SPE 184352.

Jiang R., Li K., Horne R. (2017) A mechanism study of wettability and interfacial tension for EOR using silica nanoparticles, in SPE Annual Technical Conference and Exhibition, Society of Petroleum Engineers, SPE 187096.

Kanj M., Funk J., Al-Yousif Z. (2009) Nanofluid Coreflood Experiments in the Arab-D, in Presented at the 2009 SPE Saudi Arabia Technical Symposium and Exhibition, Al khobar, Saudi Arabia, May 09-11, SPE paper 126161.

Karimi A., Fakhroueian Z., Bahramian A., Pour Khiabani N., Darabad J.B., Azin R., Arya S. (2012) Wettability alteration in carbonates using zirconium oxide nanofluids: EOR implications, Energy Fuels 26, 2, 1028-1036.

Kashefi S., Lotfollahi M.N., Shahrabadi A. (2018) Investigation of asphaltene adsorption onto zeolite beta nanoparticles to reduce asphaltene deposition in a silica sand pack, Oil Gas Sci. Technol. - Rev. IFP Energies nouvelles 73, 2. 
Kim S.J., Bang I.C., Buongiorno J., Hu L.W. (2007a) Surface wettability change during pool boiling of nanofluids and its effect on critical heat flux, Int. J. Heat Mass Transfer 50, 19-20, 4105-4116.

Kim S.J., Bang I.C., Buongiorno J., Hu L.W. (2007b) Study of pool boiling and critical heat flux enhancement in nanofluids, Bull. Pol. Acad. Sci.: Tech. Sci. 55, 211-216.

Kondiparty K., Nikolov A.D., Wasan D., Liu K.L. (2012) Dynamic spreading of nanofluids on solids. Part I: experimental, Langmuir 28, 41, 14618-14623.

Lee Y., Du Z., Lin W., Yang Y. (2006) Monolayer behavior of silica particles at air/water interface: a comparison between chemical and physical modifications of surface, J. Colloid Interface Sci. 296, 1, 233-241.

Li K., Hou B., Wang L., Cui Y. (2014) Application of carbon nanocatalysts in upgrading heavy crude oil assisted with microwave heating, Nano Lett. 14, 6, 3002-3008.

Li Z., Kepkay P., Lee K., King T., Boufadel M.C., Venosa A.D. (2007) Effects of chemical dispersants and mineral fines on crude oil dispersion in a wave tank under breaking waves, Mar. Pollut. Bull. 54, 7, 983-993.

Lim S., Horiuchi H., Nikolov A.D., Wasan D. (2015) Nanofluids alter the surface wettability of solids, Langmuir $3121,5827-5835$.

Luo D., Wang F., Alam M.K., Yu F., Mishra I.K., Bao J., Willson R.C., Ren Z. (2017) Colloidal stability of graphene-based amphiphilic janus nanosheet fluid, Chem. Mater. 29, 3454-3460.

Luo D., Wang F., Zhu J., Cao F., Liu Y., Li X., Ren Z. (2016) Nanofluid of graphene-based amphiphilic Janus nanosheets for tertiary or enhanced oil recovery: High performance at low concentration, in Proc. of the National Academy of Sciences 201608135.

Mcelfresh P.M., Holcomb D.L., Ector D. (2012) Application of nanofluid technology to improve recovery in oil and gas wells, in SPE International Oilfield Nanotechnology Conference and Exhibition. Society of Petroleum Engineers, SPE154827.

Metin C.O., Baran J.R. Jr, Nguyen Q.P. (2012) Adsorption of surface functionalized silica nanoparticles onto mineral surfaces and decane/water interface, J. Nanopart. Res. 14, 11, 1-16.

Moon T. (2010) Nanofluid technology promises large-scale performance gains from tight reservoirs, J. Pet. Technol.

Moradi B., Pourafshary P., Farahani F.J., Mohammadi M., Emadi M.A. (2015) Application of $\mathrm{SiO}_{2}$ nano particles to improve the performance of water alternating gas EOR process, in SPE Oil \& Gas India Conference and Exhibition, Society of Petroleum Engineers, SPE 178040.

Nares H.R., Schachat P., Ramirez-Garnica M.A., Cabrera M., Noe-Valencia L. (2007) Heavy-crude-oil upgrading with transition metals, in Latin American \& Caribbean Petroleum Engineering Conference. Society of Petroleum Engineers, SPE 107837.

Nazari Moghaddam R., Bahramian A., Fakhroueian Z., Karimi A., Arya S. (2015) Comparative study of using nanoparticles for enhanced oil recovery: Wettability alteration of carbonate rocks, Energy Fuels 29, 4, 2111-2119.

Negin C., Ali S., Xie Q. (2016) Application of nanotechnology for enhancing oil recovery - A review, Petroleum 2, 4, 324-333.

Nikolov A., Wasan D. (2014) Wetting-dewetting films: the role of structural forces, Adv. Colloid Interface Sci. 206, 207-221.

Nwidee L.N., Al-Anssari S., Barifcani A., Sarmadivaleh M., Lebedev M., Iglauer S. (2017) Nanoparticles influence on wetting behaviour of fractured limestone formation, J. Petrol. Sci. Eng. 149, 782-788.
Ogolo N.A., Olafuyi O.A., Onyekonwu M.O. (2012) Enhanced oil recovery using nanoparticles, Society of Petroleum Engineers, https://doi.org/10.2118/160847-MS.

Onyekonwu M.O., Ogolo N.A. (2010) Investigating the use of nanoparticles in enhancing oil recovery, Society of Petroleum Engineers, https://doi.org/10.2118/140744-MS.

Qiu F., Mamora D.D. (2010) Experimental study of solventbased emulsion injection to enhance heavy oil recovery in Alaska north slope area, in Canadian Unconventional Resources and International Petroleum Conference, Society of Petroleum Engineers, CSUG/SPE 136758, https://doi.org/ 10.2118/136758-MS.

Rezakazemi M., Mirzaei S., Asghari M., Ivakpour J. (2017) Aluminum oxide nanoparticles for highly efficient asphaltene separation from crude oil using ceramic membrane technology, Oil Gas Sci. Technol. - Rev. IFP Energies nouvelles $\mathbf{7 2}, 6,34$

Sethumadhavan G.N., Nikolov A.D., Wasan D.T. (2001) Stability of liquid films containing monodisperse colloidal particles, J. Colloid Interface Sci. 240, 1, 105-112.

ShamsiJazeyi H., Miller C.A., Wong M.S., Tour J.M., Verduzco R. (2014) Polymer-coated nanoparticles for enhanced oil recovery, J. Appl. Polym. Sci. 131, 15.

Sharma T., Iglauer S., Sangwai J.S. (2016) Silica nanofluids in an oilfield polymer polyacrylamide: Interfacial properties, wettability alteration and applications for chemical enhanced oil recovery, Ind. Eng. Chem. Res., 55, 48, 12387-12397.

Skauge T., Spildo K., Skauge A. (2010) Nano-sized particles for EOR, in SPE Improved Oil Recovery Symposium, Tulsa, OK, April, 24-28, Society of Petroleum Engineers: Richardson, TX, SPE-129933-MS.

Somasundaran P., Mehta S.C., Rhein L., Chakraborty S. (2007) Nanotechnology and related safety issues for delivery of active ingredients in cosmetics, MRS Bull. 32, 10, 779-786.

Suleimanov B.A., Ismailov F.S., Veliyev E.F. (2011) Nanofluid for enhanced oil recovery, J. Petrol. Sci. Eng. 78, 2, 431-437.

Sun X., Zhang Y., Chen G., Gai Z. (2017) Application of nanoparticles in enhanced oil recovery: a critical review of recent progress, Energies 10, 3, 345.

Torsater O., Li S., Hendraningrat L. (2013a) Enhancing oil recovery of low-permeability Berea sandstone through optimised nanofluids concentration, Society of Petroleum Engineers, https://doi.org/10.2118/165283-MS.

Torsater O., Li S., Hendraningrat L. (2013b) Effect of some parameters influencing enhanced oil recovery process using silica nanoparticles: An experimental investigation, Society of Petroleum Engineers, https://doi.org10.2118/165955-MS.

Trokhymchuk A., Henderson D., Nikolov A., Wasan D.T. (2001) A simple calculation of structural and depletion forces for fluids/suspensions confined in a film, Langmuir 17, 49404947.

Vafaei S., Wen D.S. (2010) Bubble formation in a quiescent pool of gold nanoparticle suspension, Adv. Colloid Interface Sci. 159, 10, 72-93.

Verga F., Lombardi M., Maddinelli G., Montanaro L. (2017) Introducing core-shell technology for conformance control, Oil Gas Sci. Technol. - Rev. IFP Energies nouvelles 72, 1, 5.

Wasan D.T., Nikolov A.D. (2003) Spreading of nanofluids on solids, Nature 423, 156-159.

Wasan D., Nikolov A., Kondiparty K. (2011) The wetting and spreading of nanofluids on solids: Role of the structural disjoining pressure, Curr. Opin. Colloid Interface Sci. 16, 4, 344-349. 
Wen D.S. (2008) On the role of structural disjoining pressure to boiling heat transfer with thermal nanofluids, J. Nanopart. Res. 10, 7, 1129-1140.

Worthen A.J., Bryant S.L., Huh C., Johnston K.P. (2013) Carbon dioxide-in-water foams stabilized with nanoparticles and surfactant acting in synergy, AIChE J. 59, 9, 3490-3501.

Worthen A.J., Foster L.M., Dong J., Bollinger J.A., Peterman A.H., Pastora L.E., Bryant S.L., Truskett T.M., Bielawski C.W., Johnston K.P. (2014) Synergistic formation and stabilization of oil-in-water emulsions by a weakly interacting mixture of zwitterionic surfactant and silica nanoparticles, Langmuir 30, 4, 984-994.

Xiang W., Zhao S., Song X., Fang S., Wang F., Zhong C., Luo Z. (2017) Amphiphilic nanosheet self-assembly at the water/oil interface: computer simulations, Phys. Chem. Chem. Phys. 19, 11, 7576-7586.

$\mathrm{Yu}$ W., Xie H. (2012) A review on nanofluids: Preparation, stability mechanisms, and applications, J. Nanomater. 2012, 1.

Zhang H., Nikolov A., Wasan D. (2014a) Enhanced oil recovery (EOR) using nanoparticle dispersions: Underlying mechanism and imbibition experiments, Energy Fuels 28, 5, 3002-3009.

Zhang H., Nikolov A., Wasan D. (2014b) Dewetting film dynamics inside a capillary using a micellar nanofluid, Langmuir 30, 31, 9430-9435.

Zhang H., Ramakrishnan T.S., Nikolov A., Wasan D. (2016) Enhanced oil recovery driven by nanofilm structural disjoining pressure: Flooding experiments and microvisualization, Energy Fuels 30, 4, 2771-2779. 